\title{
Nanofiltration for drinking water treatment: a review
}

\author{
Hao Guo ${ }^{1 *}$, Xianhui $\mathrm{Li}^{2 *}$, Wulin Yang ${ }^{3}$, Zhikan Yao $^{4}$, Ying Mei ${ }^{5}$, Lu Elfa Peng ${ }^{1}$, Zhe Yang ${ }^{1}$, Senlin Shao (凶) $)^{6}$, \\ Chuyang Y. Tang $(\bowtie)^{1}$ \\ 1 Membrane-based Environmental \& Sustainable Technology (MembEST) Group, Department of Civil Engineering, The University of Hong Kong, \\ Hong Kong, China \\ 2 Key Laboratory for City Cluster Environmental Safety and Green Development of the Ministry of Education, Institute of Environmental and \\ Ecological Engineering, Guangdong University of Technology, Guangzhou 510006, China \\ 3 College of Environmental Science and Engineering, Peking University, Beijing 100871, China \\ 4 College of Chemical and Biological Engineering, Zhejiang University, Hangzhou 310027, China \\ 5 Research and Development Center for Watershed Environmental Eco-Engineering, Advanced Institute of Natural Sciences, Beijing Normal \\ University, Zhuhai 519087, China \\ 6 School of Civil Engineering, Wuhan University, Wuhan 430072, China
}

(C) Higher Education Press 2021

\begin{abstract}
In recent decades, nanofiltration (NF) is considered as a promising separation technique to produce drinking water from different types of water source. In this paper, we comprehensively reviewed the progress of NFbased drinking water treatment, through summarizing the development of materials/fabrication and applications of NF membranes in various scenarios including surface water treatment, groundwater treatment, water reuse, brackish water treatment, and point of use applications. We not only summarized the removal of target major pollutants (e.g., hardness, pathogen, and natural organic matter), but also paid attention to the removal of micropollutants of major concern (e.g., disinfection byproducts, per- and polyfluoroalkyl substances, and arsenic). We highlighted that, for different applications, fit-for-purpose design is needed to improve the separation capability for target compounds of NF membranes in addition to their removal of salts. Outlook and perspectives on membrane fouling control, chlorine resistance, integrity, and selectivity are also discussed to provide potential insights for future development of high-efficiency NF membranes for stable and reliable drinking water treatment.
\end{abstract}

Keywords nanofiltration, drinking water, disinfection byproducts, micropollutants, selectivity

Received May 13, 2021; accepted July 28, 2021

E-mails: shaosenlin@whu.edu.cn (Shao S), tangc@hku.hk (Tang C Y)

${ }^{*}$ These authors contributed equally to this work.

\section{Introduction}

Water scarcity and pollution at a global scale are grand challenges in the modern society [1,2]. According to the United Nations, $30 \%$ global population does not have the access to safe and reliable drinking water services, which drives United Nations to include the universal drinking water supply in their sustainable development goals [3]. Effective water treatment and management strategies are urgently called to achieve the goal through eliminating water pollution and producing clean drinking water. Membrane-based separation techniques such as reverse osmosis (RO) and nanofiltration (NF) are considered as promising candidates for reliable production of drinking water [4]. RO is mainly used for seawater desalination, which has rigorous criteria on the rejection of $\mathrm{NaCl}$ (e.g., normally $\geqslant 99 \%$ ) [5]. Such high $\mathrm{NaCl}$ rejection generally requires a dense rejection layer who often comes at the expense of high energy consumption and low water permeability. In comparison, NF membranes have relatively loose structure to allow faster water production with lower energy requirement [6]. Meanwhile, NF membranes can be designed and optimized in a more flexible way to maximize their efficiency on drinking water production according to the different application scenarios (Fig. 1).

Since its first introduction at the late 1980s, NF membranes have been developed and optimized with improved separation performance through tuning their material compositions and structural properties $[7,8]$. Existing NF membranes often possesses the state-of-theart thin film composite (TFC) structure, consisting of a thin rejection layer (e.g., polyamide), a porous substrate layer, 


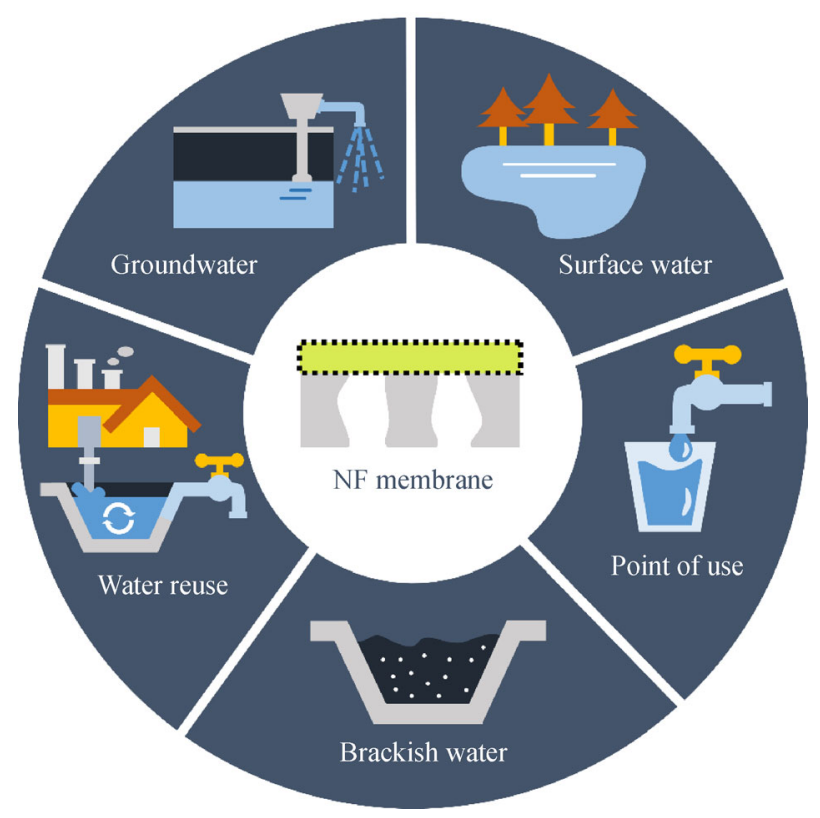

Fig. 1 Various application scenarios of NF technique, including surface water treatment, groundwater treatment, water reuse, brackish water treatment, and point of use applications.

and a non-woven fabric support [9]. The TFC structure allows independent optimization of rejection and support layer, which offers great flexibility for the design and fabrication of high-performance NF membranes [10]. In principal, the top thin rejection layer plays a critical role on NF membrane separation performance. Various approaches such as interfacial polymerization (IP) [11], surface coating/grafting [12], layer-by-layer deposition [13], and so-gel process [14], can be used to fabricate the thin layer.

Generally, NF membranes possess an effective pore size around $0.5-2 \mathrm{~nm}$ with a corresponding molecular weight cut-off (MWCO) ranging from 100 to $1000 \mathrm{Da}[6,15]$. These features enable NF membranes to achieve effective removal of suspended solids, colloidal, bacteria, and organics, as well as partial removal of dissolved ions, while most of the components are listed as the target pollutants for drinking water treatment [16]. Compared with traditional drinking water treatment methods, NF enjoys several advantages including: 1) small footprint and ease of automation, 2) wide-spectrum removal of various water contaminants to ensure high product water quality, and 3) flexibility to adapt different feed water quality. On the other hand, the operational cost, membrane fouling, and long-term stability shall also be considered to comprehensively evaluate the capability of NF for drinking water production. In view of the great potential of NFbased drinking water treatment to address the critical challenge of water scarcity and pollution, it is important to timely and thoroughly review the progress of NF technique for water purification in terms of material development, membrane fabrication, and practical applications.
Although several reviews on NF membranes have been published [17-21], they either lack of strong emphasis on the specific application scenario of drinking water treatment, or have limited timelines to include latest research findings.

In this review, we comprehensively summarize the recent research progress on NF-based drinking water treatment. NF membrane materials and their fabrication approaches are first introduced to provide basic information on the technique development (Section 2). Subsequently, the practical applications of NF membranes for drinking water treatment under different scenarios are presented, namely, surface water treatment (Section 3), groundwater treatment (Section 4), water reuse (Section 5), brackish water treatment (Section 6), and point of use applications (Section 7). Based on the membrane performance for various applications, perspectives on the challenges and future development of NF membranes for drinking water production are also discussed.

\section{NF membrane materials and fabrication}

\subsection{Polymeric NF membranes}

The majority of existing NF membranes has a TFC structure consisting of a thin polyamide layer, a porous substrate layer (e.g., polysulfone or polyethersulfone), and a non-woven support [9]. Figure 2 shows the fabrication strategy of polyamide-based NF membranes, the morphology and structure of a NF270 membrane, as well as their separation performance and application potential. The 
polyamide is generally fabricated by performing the IP reaction between an aqueous amine solution containing piperazine or $m$-phenylenediamine and an organic solution containing trimesoyl chloride (Fig. 2(a)). The formed polyamide layer (Figs. 2(b) and 2(c)) plays a critical role on membrane separation performance. Nevertheless, the separation performance of polyamide membranes are often limited by the trade-off between membrane permeability and selectivity (Fig. 2(d)) [22]. To break the limitation, various strategies were explored to improve membrane separation efficiency (Fig. 2(e)). For example, nanomaterials can be introduced into the polyamide layer via adding them in the aqueous/organic phase during IP reaction, forming thin-film nanocomposite (TFN) membranes [23]. These incorporated nanomaterials in TFN membranes not only create vast nanochannels for enhanced water transport [24] but also introduce beneficial functions such as antimicrobial properties [25]. Alternatively, constructing an interlayer onto the support membrane before the IP process has been confirmed as an effective approach to regulate the properties of polyamide layer with enhanced membrane separation performance $[26,27]$. The incorporation of the interlayer could not only facilitate the formation of better-quality polyamide rejection layer (e.g., through fine-tuning reaction rate and the extent of the IP reaction $[28,29])$ but also optimize the water transport pathways in the dense polyamide rejection layer by acting as a highpermeability gutter layer [26]. These synergistical effects could simultaneously improve membrane water permeance (up to an order of magnitude) and rejection of solutes [29].

(a)
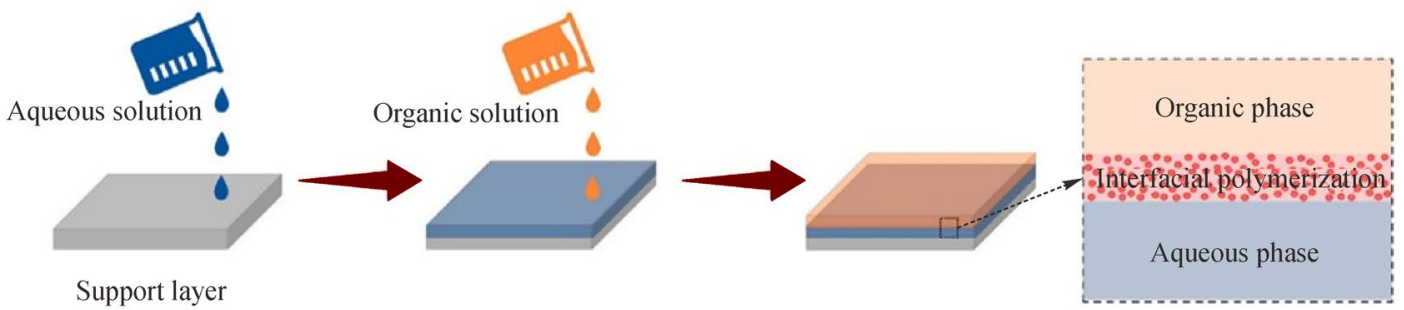

(b)

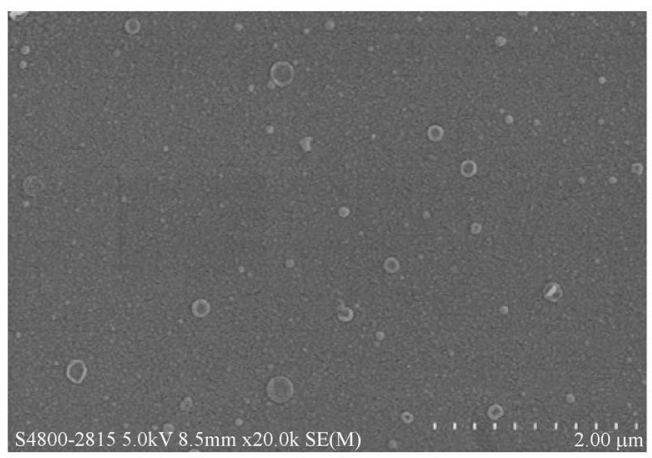

(d)

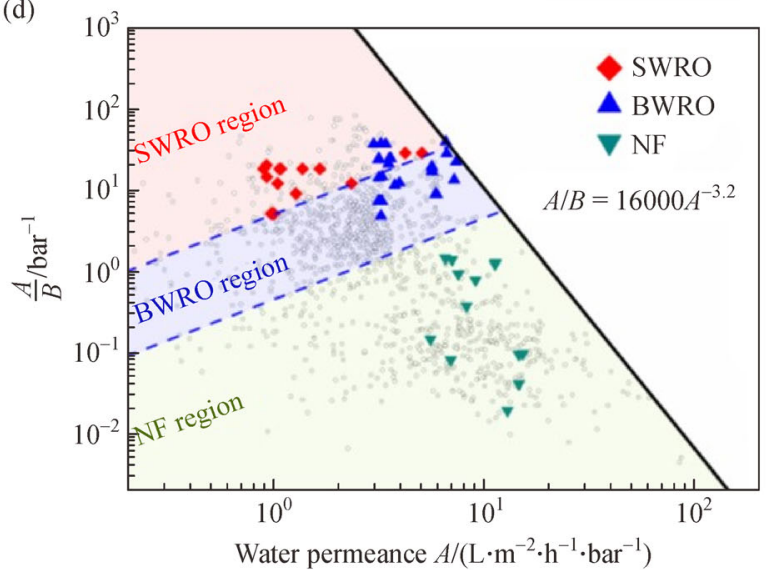

(c)

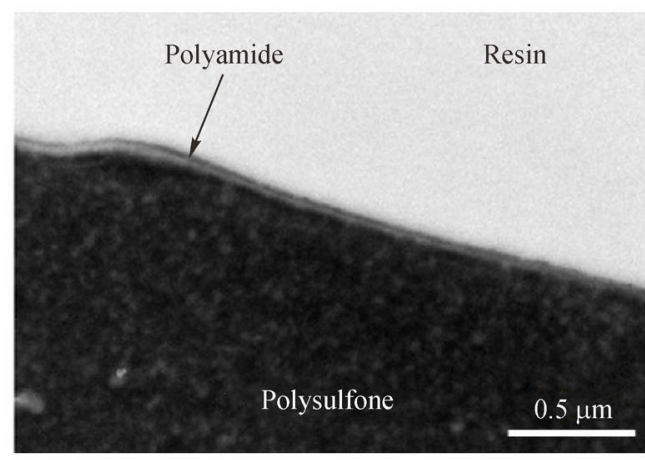

(e)

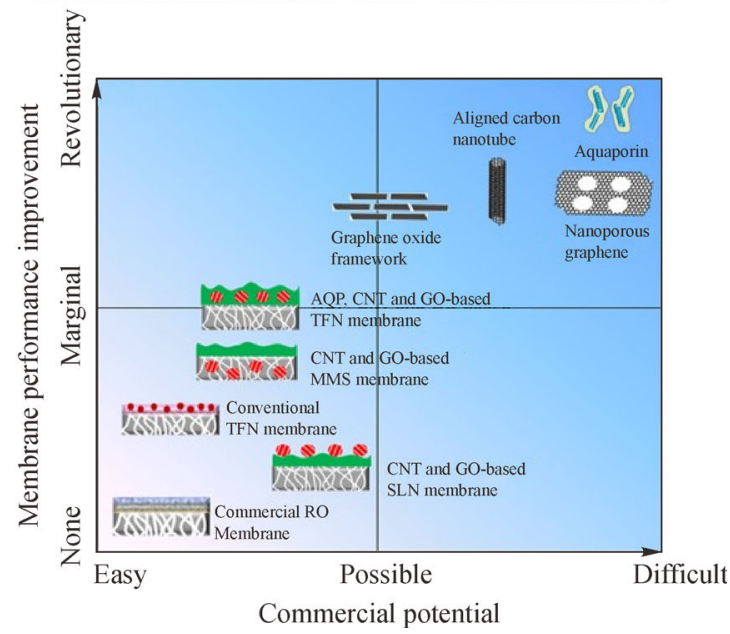

Fig. 2 (a) Schematic of interfacial polymerization process, (b) scanning electron microscope image of the surface for NF270 membrane, (c) transmission electron microscope image of the cross-section for NF270 membrane, (d) the upper bound of TFC polyamide membranes for desalination, and (e) comparison of membrane performance improvement and commercial potential of the TFC polyamide membranes. These figures are reprinted from ref. [22,30-33] with copyright permission. 
As a result, this TFN structure with an interlayer (TFNi) is promising to break the longstanding permselectivity tradeoff effects (also known as the upper bond [22]) owing to their largely improved permeability without compromising solutes retention.

In addition to polyamide, alternative polymers, such as polyurethanes, poly(bio-amides), polyanilines, polyesters, and polyimides, can also be used as membrane rejection layer materials through IP reaction (Table 1) [34]. Cellulose-based NF membranes are also commercially available, who have been used for water purification since their successful fabrication in the 1960s [35]. For example, cellulose acetate NF membrane was used to remove organic micropollutants from drinking water [36], and encountered low membrane fouling because of the hydrophilicity of the cellulose material. However, cellulose-based membranes (e.g., cellulose acetate) have relatively low tolerance to $\mathrm{pH}(2-8)$ and thermal $\left(<30^{\circ} \mathrm{C}\right)$ change, which greatly restricts their applications [37]. In addition, sulfonated polyethersulfone is also used as the rejection layer of some commercially available NF membranes (e.g., NTR-7450, Nitto Denko, Japan) [38]. The existence of sulfonate group leads to a negatively charged membrane surface, which could benefit to the rejection of anions as a result of electrostatic repulsion [39].

Polyelectrolyte NF membranes fabricated by layer-bylayer assembly have also been investigated for water treatment [45]. The chemistry and structure of polyelectrolyte membranes can be tuned via controlling the polyelectrolyte types and number of deposited bilayers during layer-by-layer procedure. An extension of this technique is the electrospray-enabled layer-by-layer fabrication of NF membranes (also called three-dimensional printing) [46]. This technique allows the control of membrane structure vie adjusting electrospray conditions, which could fabricate thinner and more uniform membranes with enhanced separation performance.

\subsection{Non-polymeric NF membranes}

Ceramic membranes with superior physical and chemical stabilities have also gained a growing interest. Similar to polymeric membranes, ceramic NF membranes generally possess average pore size of 1-2 nm with effective MWCO ranging from 200 to $1000 \mathrm{Da}$ [14]. As presented in Table 2, the nanoparticles of metal oxides such as $\mathrm{SiO}_{2}, \mathrm{TiO}_{2}$, and $\mathrm{ZrO}_{2}$ are often used as the selective layer of ceramic NF membranes, which are usually fabricated through the solgel process [14]. In addition to single kind of metal oxide nanoparticles, the composite ceramic NF membranes using mixed metal oxide, such as $\mathrm{ZrO}_{2} / \mathrm{TiO}_{2}$, have also been commercially produced to improve membrane separation performance [47]. However, the water permeability of ceramic NF membrane is often lower than that of polymeric NF membranes with similar MWCO, which can be attributed to their lower porosity and higher thickness. To improve membrane porosity, additional sacrificial pore-foaming agents (e.g., cotton, starch, polymer beads, graphite, and $\mathrm{Ni}$ ) could be introduced into the ceramic slurry [48]. In addition to sol-gel processes, other advanced fabrication methods, such as atomic layer deposition (ALD) and chemical vapor deposition (CVD) (Fig. 3), are also explored to prepare a more uniform and tight separation layer [49].

In addition to polymeric and ceramic membranes, emerging NF membranes fabricated by novel nanomaterials have attracted increasing attentions in recent years. For example, two-dimensional (2D) materials (such as $\mathrm{MoS}_{2}$, graphene, graphene oxide, metal-organic frameworks, MXene, and covalent organic frameworks) exhibited high potential for NF membrane fabrication [51,52]. In general, 2D materials possess unique physicochemical properties (e.g., nanochannel size and thickness) which allow precise separation and thus enhance membrane selectivity. The 2D material-based NF membranes can be fabricated through physical stacking [53], chemical bonding [54], electro-assisted deposition [55], etc.

Currently, polyamide-based NF membranes are most commonly used for drinking water production owing to the matured fabrication technique, successful applications in separation industries, and reasonable cost-effectiveness [19]. Ceramic NF membranes also have great potential for drinking water treatment owing to their high chemical stability, which allows them to be used with oxidants (e.g., $\mathrm{Cl}$ ) for disinfection and membrane cleaning [56]. However,

Table 1 Materials used for NF membrane preparation via IP

\begin{tabular}{|c|c|c|c|c|}
\hline Material & Advantage & Drawback & Field of application & Ref. \\
\hline Polyamide & $\begin{array}{l}\text { Matured fabrication and high } \\
\text { separation performance }\end{array}$ & Vulnerable to chlorination & Membranes mainly for NF and RO & [9] \\
\hline Poly(bio-amide) & $\begin{array}{l}\text { Biocompatibility and } \\
\text { switchable properties }\end{array}$ & Relatively high MWCO values & $\begin{array}{l}\text { NF applications with high } \\
\text { permeability }\end{array}$ & [34] \\
\hline Polyester & $\begin{array}{l}\text { High resistance to } \\
\text { chlorine }\end{array}$ & $\begin{array}{c}\text { Susceptibility to hydrolytic } \\
\text { degradation }\end{array}$ & $\begin{array}{l}\text { NF applications with improved } \\
\text { chlorine stability }\end{array}$ & {$[40,41]$} \\
\hline Polyimide & $\begin{array}{l}\text { High tolerance to organic } \\
\text { solvent and thermal stability }\end{array}$ & $\begin{array}{l}\text { Instability of amic acid } \\
\text { groups in water }\end{array}$ & Organic solvent NF & {$[42]$} \\
\hline Polyaniline & Electrochemical properties & $\begin{array}{l}\text { Difficult to control } \\
\text { nanostructures }\end{array}$ & $\begin{array}{l}\text { Organic solvent NF and } \\
\text { electrically conductive membranes }\end{array}$ & {$[43,44]$} \\
\hline
\end{tabular}




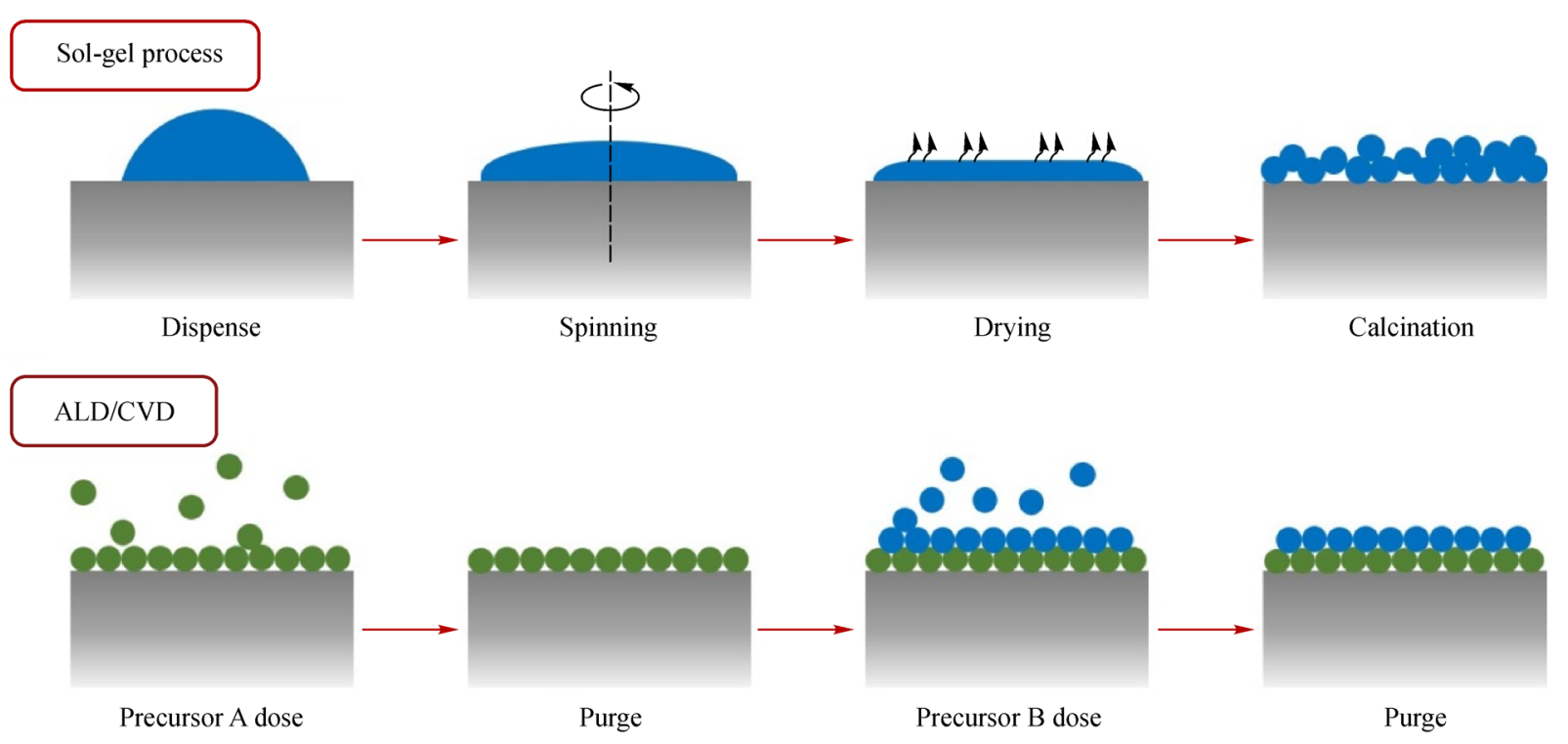

Fig. 3 Schematic illustration of sol-gel and ALD/CVD processes.

Table 2 Key features of various ceramic NF membranes and commercially available products ${ }^{\text {a) }}$

\begin{tabular}{lcccc}
\hline Material & MWCO/Da & Fabrication method & Product \\
\hline $\mathrm{SiO}_{2}$ & 600 & Colloidal sol-gel method & Ceramic Inopor ${ }^{\mathbb{R}}$ membrane \\
$\mathrm{TiO}_{2}$ & $200-1000$ & $\begin{array}{c}\text { Colloidal sol-gel method; } \\
\text { electrophoretic deposition }\end{array}$ & $\begin{array}{c}\text { Fine UF N001 of TAMI Industries and } \\
\text { Ceramic Inopor }{ }^{\circledR} \text { membrane }\end{array}$ & [14] \\
$\mathrm{ZrO}_{2}$ & $350-400$ & Colloidal sol-gel method & - & {$[14]$} \\
$\mathrm{ZrO}_{2} / \mathrm{TiO}_{2}$ & $400-500$ & Colloidal sol-gel method & - & {$[14]$} \\
\hline
\end{tabular}

a) According to the literature, the price of commercial ceramic NF membrane is around $1000-2500 \mathrm{USD} \cdot \mathrm{m}^{-2}[50]$.

the application of ceramic membranes in drinking water treatment is largely limited due to the high cost (e.g., up to 10 times of the cost for polymeric membranes [50]). In recent decades, the development of novel materials (e.g., $2 \mathrm{D}$ materials) is also driving the fabrication of highperformance NF membranes using such materials $[57,58]$. Nevertheless, these emerging membranes using novel materials/fabrication methods are mainly investigated at laboratory-scale, their full-scale manufacturing is facing various challenges (e.g., low production rate, high cost, etc.). Future research needs to pay more attention to the scale-up of novel membranes and their performance for realistic applications.

\section{NF for surface water treatment}

Surface water, the water in a river, stream, creek, lake, and reservoir, is the major source of drinking water. In China, surface water accounted for $84.2 \%$ of the total water supply in 2019. In general, surface water possesses relatively high quality with a total dissolved solids less than $1000 \mathrm{mg} \cdot \mathrm{L}^{-1}$. However, the water quality is easily affected by runoff, rainfall, point/non-point source pollution, etc. Consequently, the water quality may seasonally fluctuate [59] with potential contamination from various contaminants such as synthetic organic compounds [60]. Moreover, surface water is likely to be accidentally polluted by chemical discharge and algal blooms [61].

Conventional treatment process (coagulation-sedimentation-filtration-disinfection) is mostly used for the purification of surface water. This conventional process is designed for the removal of particles and pathogens, and may not effectively remove some emerging pollutants [62]. More importantly, in the unit process of disinfection, disinfection byproducts (DBPs) are formed because of the reaction between the disinfectants and precursors in surface water, such as natural organic matter (NOM) and bromide. Because NF membrane could reject most of organic matters, it becomes an alternative to address above challenges in addition to existing treatment system.

\subsection{NF system for surface water treatment}

In 1999, the world's first large-scale water treatment plant using NF, i.e., Méry-sur-Oise plant, was built in France. 
The plant had a production capacity of $140000 \mathrm{~m}^{3} \cdot \mathrm{d}^{-1}$ and could effectively remove the NOM and pesticides in the feed river water [63]. In China, although NF has been used for saline water treatment for many years (total dissolved solids is the major concern), it has not been specifically used for the control of DBPs and other pollutants in drinking water until recent years. For example, a 300000 $\mathrm{m}^{3} \cdot \mathrm{d}^{-1} \mathrm{NF}$-based water plant is under construction in Zhangjiagang City of China, who will use NF to treat the Yangtze River water to improve the quality of drinking water.

A typical NF system for surface water purification consists of pretreatment process, membrane process, and posttreatment process (Fig. 4). Because of the relatively high NOM content in surface water, the priority of pretreatment is to reduce the risks of membrane fouling for NF unit. The commonly used pretreatment processes include coagulation, flocculation, sedimentation, sand filtration, microfiltration, and ultrafiltration [64-66]. These pretreatments could largely remove particles, organic matters, and bacteria, thereby reducing membrane fouling in NF units. After filtering through the NF membrane, most of the pollutants are removed. However, alkalinity is also partially removed during pretreatment, resulting in high corrosion potential. Therefore, stabilizing chemicals such as sodium carbonate and lime should be added to adjust the water alkalinity [64]. A more flexible approach for water stabilization is to blend the effluent of the pretreatment units (i.e., the feed of NF unit) with the NF permeate (Fig. 4), while this approach was practiced by Kaotan Water Treatment Plant $\left(300000 \mathrm{~m}^{3} \cdot \mathrm{d}^{-1}\right.$, Taiwan, China) [67]. Before entering to the distribution system, the treated water needs chlorination to prevent the regrowth of bacteria in the pipe network.

\subsection{Control of DBPs formation}

The NF membrane could effectively remove microorganisms, divalent ions, heavy metal ions, NOMs, and many trace organic matters [7]. Here, we mainly discuss the major issues of controlling DBPs in the surface water treatment system. The removal of organic contaminants, pathogens, and dissolved ions will be discussed in Section $5 \mathrm{NF}$ for water reuse and Section $6 \mathrm{NF}$ for brackish water treatment.

Disinfection is a vital step to eliminate the concerns of pathogens in drinking water. However, the process has high tendency to generate toxic DBPs associated with healthy concerns [68]. Most DBPs are formed by the reaction between chlorine/chloramines (disinfectants) and the precursors such as NOM [69]. Typical DBPs include trihalomethanes, haloacetic acids, and $N$-nitrosodimethylamine. NF has a high rejection of NOM $(50 \%-95 \%)$ [70], which could largely suppress the formation of DBPs in subsequent disinfection. For example, commercial NF membranes (ESNA, TS80, and NF270) could achieve a removal rate of $72 \%-97 \%$ and $57 \%-83 \%$ for $N$-nitrosodimethylamine and trihalomethanes, respectively [71]. For the world's first large-scale NF water treatment plants (i.e., Méry-sur-Oise plant), the trihalomethanes reduced by $50 \%$ in their distribution system after introducing NF process [72]. In addition to chlorine, the presence of bromine can also increase the generation of DBPs and shift the speciation to brominated species. However, NF shows low rejection for bromide $(<30 \%)$ [73]. The low removal of bromide coupled to the high removal of NOM could shift the trihalomethanes and haloacetic acids to more brominated species during the chlorination of NF permeate [74]. Because NF process has a high removal of pathogen (physical disinfection), the dosage of chlorine could be reduced in the following disinfection unit [75], which could also reduce the formation of DBPs and the odor of chlorine in tap water. In short, NF process can effectively remove the DPBs precursors and decrease the chlorine dosage, thereby effectively reducing the DBPs formation.

\section{NF for groundwater treatment}

Groundwater is an important natural resource serving for agricultural irrigation and drinking water supply in most countries over the globe [76]. Many groundwaters contain high concentration of hardness ions such as $\mathrm{Ca}$ and $\mathrm{Mg}$ due to ambient geochemical conditions, and these ions have to be removed prior to use [77]. Meanwhile, with the intensified chemical use and continuous discharge of industrial waste, groundwater quality has been greatly hampered and resulted in numerous contaminated sites [78]. Emerging contaminants such as per- and polyfluoroalkyl substances (PFASs) and As appeared in the groundwater and posed great health concern to humans $[79,80]$. NF technology, as a technology for multicontaminants removal, are thus required to purify groundwater for drinking purpose.

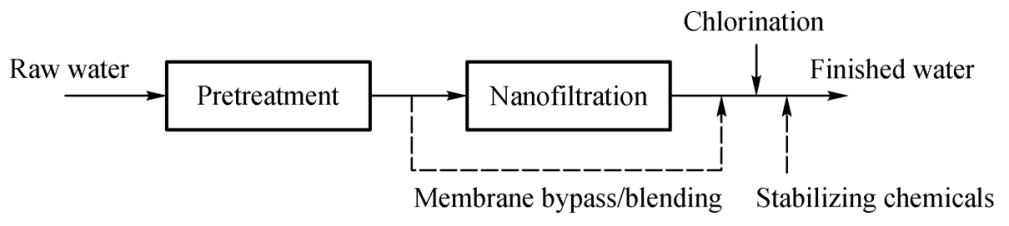

Fig. 4 A typical NF system for surface water purification. 


\subsection{Hardness removal}

NF membranes have been used for hardness removal in groundwater treatment for decades [81]. The immerging use of NF membranes originates from two reasons: 1) traditional high-pressure RO membranes resulted in high energy cost; 2) the permeate quality was often too good and required post remineralization [82]. NF membranes possessed moderate rejections with higher fluxes compared to high pressure RO membranes, which make $\mathrm{NF}$ advantageous for hardness removal in groundwater treatment. NF membranes can typically achieve $>98 \%$ removal of $\mathrm{Ca}$ and $\mathrm{Mg}$, through size exclusion mechanism $[83,84]$. As $\mathrm{Ca}$ is essentially beneficial for human health, recent research started focusing on enlarging the pore size of NF through incorporation of a high molecular weight bipiperidine monomer during the IP to form a loose, nanoporous selective layer structure, which selectively rejected sulfate while partially passing through $\mathrm{Ca}$ ion [85]. The fabricated NF membrane not only maximized water permeability but also reduced membrane scaling due to less $\mathrm{CaSO}_{4}$ accumulation on membrane surface. It provides important insights for future groundwater treatment adopting NF processes with strong emphasis on tailoring the selectivity and permeability of NF with enhanced water recovery.

\subsection{As and PFASs removal}

Figure 5 illustrates the rejection mechanisms of As and PFASs under different water chemistry by NF membranes. As has now become a typical toxic element in groundwater systems due to geochemical occurrence and industrial pollution, and posed elevated health risks such as skin and lung cancer [86,87]. Common forms of As in groundwater are trivalent arsenite, i.e., As(III), and pentavalent arsenate, i.e., $\operatorname{As}(\mathrm{V})$, with concentration ranges from $<0.05 \mathrm{ppb}$ up to $5000 \mathrm{ppb}[88]$. The $\mathrm{As}(\mathrm{III})$ and $\mathrm{As}(\mathrm{V})$ rejections by $\mathrm{NF}$ varied depending on different charge states. The rejection of uncharged $\mathrm{As}$ (III) by NF membranes is mainly governed by size exclusion, while it often suffered lower rejections of $<90 \%[88,89]$. In comparison, NF membranes could achieve high rejection of $96 \%-99 \%$ for negatively charged $\mathrm{As}(\mathrm{V})$ thanks to the combined effects of electrostatic repulsion and size exclusion (Fig. 5(a)) [79,90]. Peroxidation of $\mathrm{As}(\mathrm{III})$ to $\mathrm{As}(\mathrm{V})$ is a viable method and can be integrated with NF process to boost the overall arsenic removal efficiency [91]. Therefore, it is important to have adequate knowledge of As speciation and ambient aqueous chemistry condition for the efficient removal of As during groundwater purification with NF technology. Moreover, tailoring the pore size of NF membranes with enhanced effect of size exclusion might be another way for removing uncharged As(III) form [92].

PFASs are a class of emerging contaminants that are persistent in groundwater and resistant to natural degradation process [95-97]. PFASs have been shown to be bioaccumulative and toxic at trace concentrations, thereby causing great health concerns $[98,99]$. NF membranes are likely to achieve relatively high rejection of $>95 \%$ of PFASs, which allows them to purify groundwater with fluctuating PFASs concentrations and ensure stable permeate quality [100-102]. The removal of PFASs by $\mathrm{NF}$ membranes is mainly governed by size exclusion in addition to electrostatic repulsion between anionic PFASs and negatively charged membrane surface. For example, NF270 membrane has an average pore size of $0.88 \mathrm{~nm}$ [31], which is significantly smaller than the molecule size of $1.09 \mathrm{~nm}$ for PFOS, resulting in a high PFOS rejection of $>95 \%$ by the membrane [94]. The rejection could be further enhanced with increasing the $\mathrm{pH}$ of feed solution as a result of stronger electrostatic repulsion at high $\mathrm{pH}$ [94]. Nevertheless, further research on the efficacy and mechanism of PFASs removal by NF under different fouling (a)

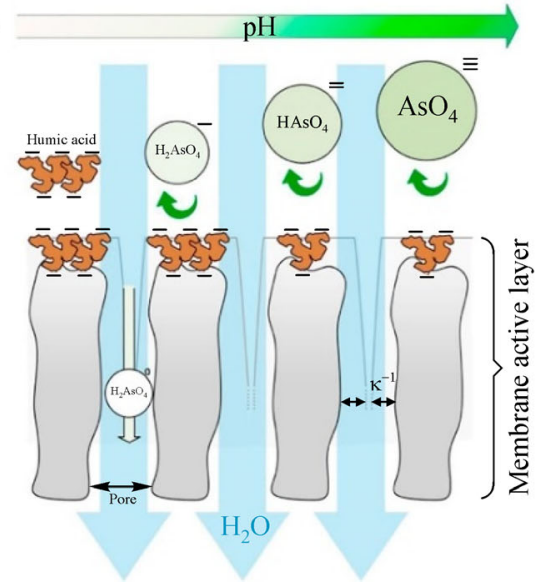

(b)

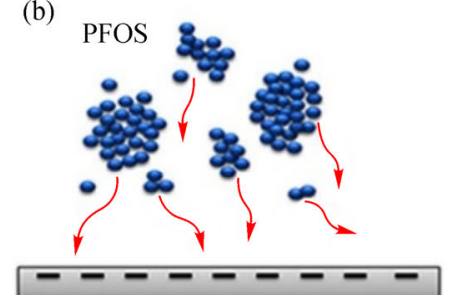

NF 270 membrane

Low resistance

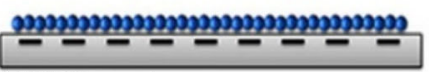

NF 270 membrane

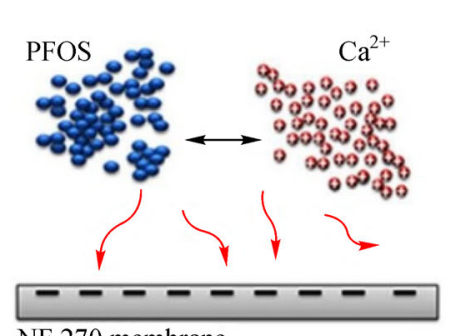

NF 270 membrane

High resistance

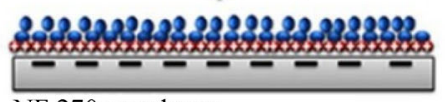

NF 270 membrane

Fig. 5 (a) Schematic diagram presenting the removal of $\mathrm{As}(\mathrm{V})$ at different $\mathrm{pH}$ and fouling condition by a NF membrane. Reprinted with permission from ref. [93], copyright 2021, Elsevier BV. (b) Illustration of perfluorooctane sulfonate (PFOS) removal at the presence of calcium. Reprinted with permission from ref. [94], copyright 2013, Elsevier BV. 
conditions and water matrices is still needed (Fig. 5(b)). In addition, it is also worthwhile to explore the control of emerging PFASs (e.g., hexafluoropropylene oxide dimer acid, also known as GenX) using NF membranes [103].

The use of NF in groundwater purification is an all-inone approach to concurrently remove hardness, organic matters, and micropollutants. Previous studies generally focused on removing one or two targeted species, while groundwater is usually complex and consists of varied substances. Tailoring the separation properties of NF membranes for complex types of groundwater is important in future studies to balance the trade-off between permeability and selectivity [104]. Developing novel NF membranes with environmentally friendly materials and manufacturing processes is also needed for sustainable development.

\section{$5 \quad$ NF for water reuse}

In addition to conventional water source (e.g., surface water and groundwater), wastewater is also considered as a supplementary source to produce potable/non-potable water through membrane-based water reuse [105]. In fact, some countries/regions with limited water source (e.g., Singapore, California, and Australia) have integrate reused water into their drinking water supply system for decades [106,107]. For example, Singapore has recognized the reused water (known as NEWater) as one of their national taps, contributing up to $40 \%$ water supply of the country [108]. Advanced membrane separation process such as RO/NF is a vital unit in water reuse system as they can effectively remove the majority of toxic and harmful pollutants from the feed. Although RO is more competitive to produce highly purified water, NF is also considered as a qualified barrier for the removal of water pollutants in water reuse [109]. For instance, NF is often proposed to generate reused water through the treatment of textile wastewater containing large amount of dyes and salts $[110,111]$.

\subsection{Removal of organic contaminants}

The effluent of wastewater treatment plant is mainly used as the feed water for membrane-base water reuse. Compared with surface water and groundwater, the effluent tends to have more complicated water matrices even after appropriate treatment, which poses great challenges to the separation performance of NF membranes [112]. One of the challenges is to achieve effective removal of organic contaminants, a major component presented in the effluents of wastewater treatment plant associated with healthy concerns and reused water safety [113-115]. NF membrane rejection of organic contaminants is governed by several mechanisms, including size exclusion, electrostatic interactions, hydrophobic interactions, and polar effects $[116,117]$. The organic contaminants presented with hydrophilic nature and large molecular weight (e.g., higher than the MWCO of membranes) are more easily removed by NF membranes thanks to the strong size exclusion effect. For example, NF90 membrane has a MWCO of $200 \mathrm{Da}$, which allow it to achieve $>95 \%$ rejection of hydrophilic antibiotics with molecular weight ranging from 250 to 361 Da [118]. Meanwhile, NF membrane surface is often negatively charged at environmental $\mathrm{pH}$ (e.g., $\mathrm{pH}$ 6-9) which is beneficial for the removal of contaminants with negative charge (e.g., dyes and PFASs) as a result of electrostatic repulsion $[110,119]$. In contrast, positively charged organic contaminants may suffer low membrane rejection due to the Donnan effect [120].

On the other hand, organic contaminants with strong hydrophobicity and/or high polarity are often poorly rejected by NF membranes, e.g., $<50 \%$ for endocrine disrupting compounds (EDCs) by NF90 [121] and NF270 membranes [31]. The hydrophobic interactions between EDCs and membrane facilitated the partition of these compounds into membrane material (e.g., polyamide) following by the diffusion through the membrane $[122,123]$, resulting in the high permeance of EDCs (thus low rejection). Suppressing the hydrophobic interactions between compounds and membrane is an effective way to reduce the partition behavior and improve membrane rejection of hydrophobic contaminants (Fig. 6). For example, a hydrophilic polydopamine coating on a commercial NF90 membrane could significantly enhance its rejection of hydrophobic EDCs [121]. Similar phenomena were also observed in the cases of using tannic acid-iron based NF membrane (Fig. 6(a)) [118] and hydrophilic ceramic NF membrane [124] to remove hydrophobic contaminants. In addition, accelerating water transport through the membrane (i.e., enhancing membrane water permeance) is also useful to enhance membrane rejection of organic contaminants because of the dilution effects in the permeate side (Fig. 6(b)). Various strategies such as addition of porous nanofillers [125], creation of selective nanochannels [24], and introduction of interlayer [126] can prompt membrane water permeance and thus increase the rejection of contaminants.

\subsection{Pathogen removal}

Pathogens (e.g., bacteria and virus) are of critical concerns in wastewater treatment chain and are listed as the removal target with highest priority in membrane-based water reuse, especially after the global outbreak of COVID-19 [127]. Generally, the average size of pathogens (e.g., 20$300 \mathrm{~nm}$ for virus [128]) are significantly larger than the effective pore size of NF membranes $(\leqslant 2 \mathrm{~nm})$, therefore they should be completely removed by the membrane. However, there are several studies that reported incomplete 
(a)
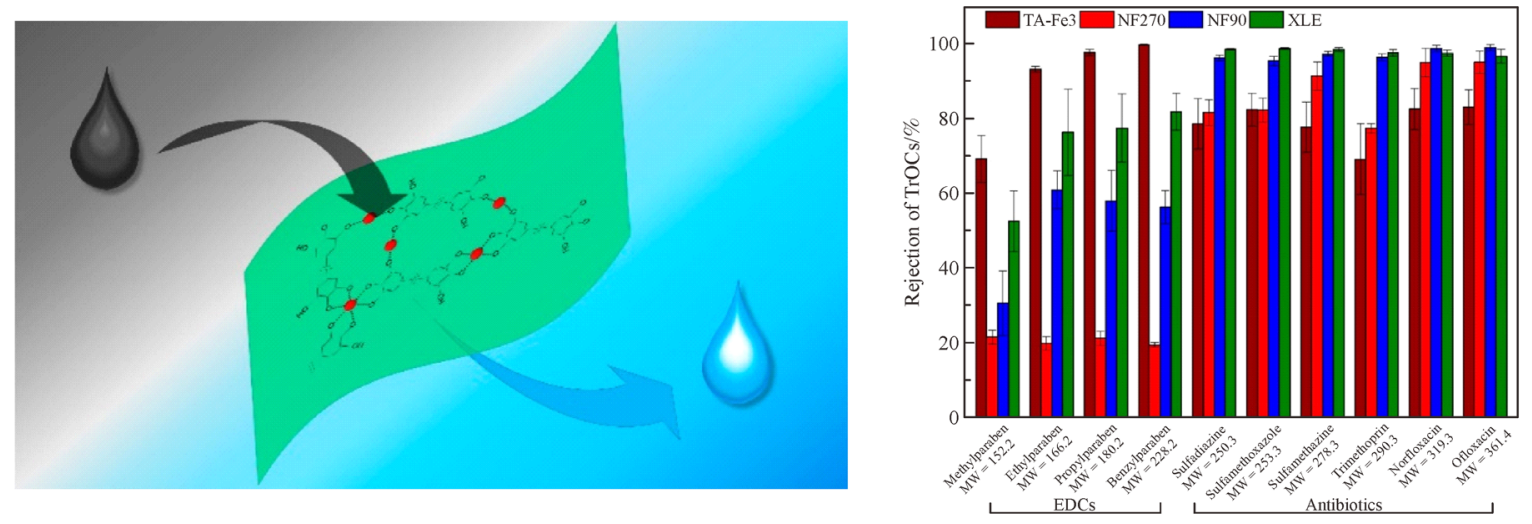

(b)
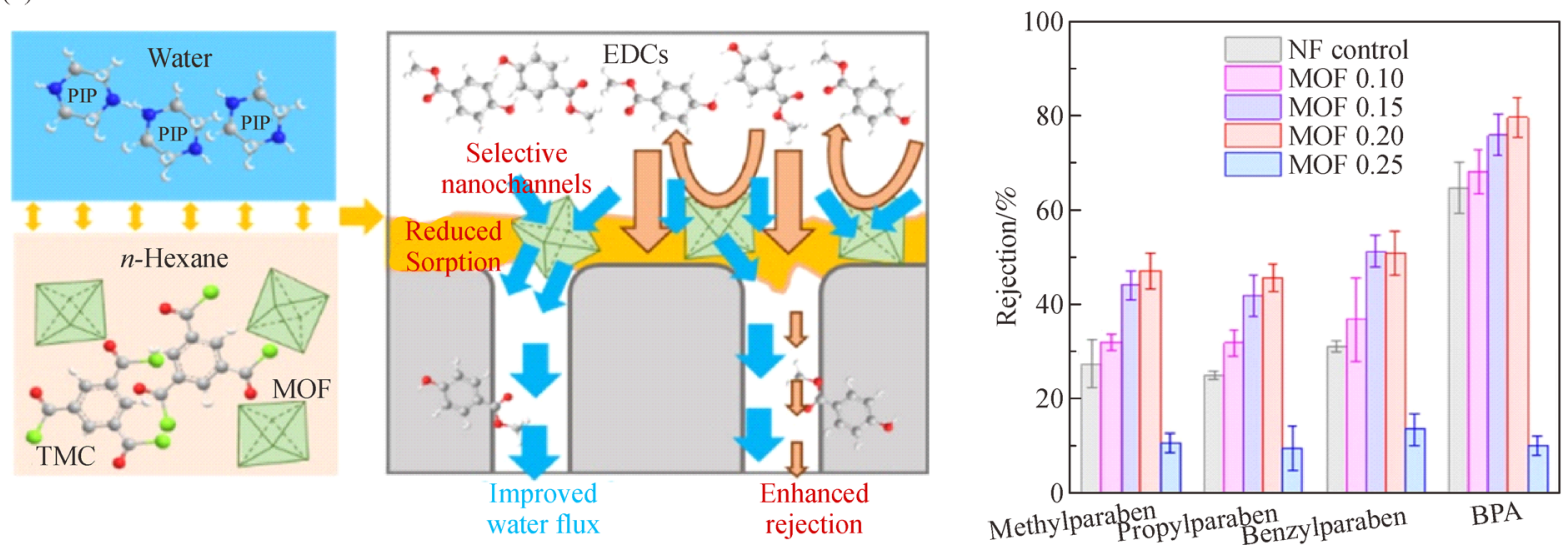

Fig. 6 (a) Removal of trace organic contaminants by a tannic acid-iron complexes-based NF membrane. Reprinted with permission from ref. [118], copyright 2019, American Chemiacl Society. (b) Incorporation of hydrophilic metal organic frameworks into a polyamide active layer for improved rejection of hydrophobic EDCs. Reprinted with permission from ref. [125], copyright 2019, American Chemiacl Society.

removal of virus and bacteria by RO membranes [129131]. For example, $\mathrm{Mi}$ et al. reported a rejection of $>99.9995 \%$ (i.e., > 5-log removal) for bacteriophage MS2 $(\sim 25 \mathrm{~nm})$ by spiral-wound RO elements [129]. A possible explanation for the incomplete rejection is that the virus may pass through the imperfections in the elements (e.g., insufficient sealing at the glue lines). In addition, a recent study reported that intrinsic nanosized defects are likely to be formed during the fabrication of polyamide NF membranes by IP [132]. The defects may serve as hot spots for virus transport, partially resulting in the incomplete rejection. To keep the safety of reused water away from pathogens, highly sensitive methods are strongly required to monitor the integrity of membrane and elements. Polishing strategies (e.g., in situ healing) may also be considered to improve membrane integrity toward satisfactory virus removal.

\section{NF for brackish water treatment}

Brackish water is one of the salinity water resources for potable use with the salinity between fresh water and seawater. Commonly, the total dissolved solids of brackish water are in the range of $1-5 \mathrm{~g} \cdot \mathrm{L}^{-1}$ with highly different compositions, such as $\mathrm{Ca}^{2+}, \mathrm{Mg}^{2+}, \mathrm{SO}_{4}{ }^{2-}, \mathrm{F}^{-}, \mathrm{NO}_{3}{ }^{-}$, and NOM. NF is an alternative separation technology with great application potential in brackish water desalination. According to the main separation mechanisms of NF, e.g., Donnan (charge) exclusion and size (steric) exclusion [133], NF can be used for the removal of hardness [81], $\mathrm{F}^{-}$ [134], and $\mathrm{NO}_{3}{ }^{-}$[135] from brackish water to improve the produced water quality or to reduce membrane scaling in the following desalination stage. Similarly, partial salts in brackish water could also be removed by NF as a result of the moderate rejection of NF membrane for monovalent salts and high rejection for divalent salts. Brackish water desalination performance of commercial TFC NF membranes were evaluated by Hilal et al. [136]. The results showed a reduced $\mathrm{NaCl}$ rejection from $95 \%$ to $41 \%$ with increasing the salinity of feed solution from to $25 \mathrm{~g} \cdot \mathrm{L}^{-1}$. Gekas et al. used NF membrane to treat brackish groundwater with a high hardness [137], and the NF membrane gave a relatively high water flux of $15-47 \mathrm{~L} \cdot \mathrm{m}^{-2} \cdot \mathrm{h}^{-1}$ 
together with a hardness removal of $70 \%-76 \%$ and salt rejection of $44 \%-46 \%$. Other candidates for brackish water treatment, such as RO and electrodialysis were also studied and compared with NF [138]. The results showed that NF permitted to reduce the concentrations of divalent ions, but the total dissolved solids of the produced water was still higher than World Health Organization standard. In addition to commercial membranes, novel NF membranes were also explored to improve the efficiency of brackish water treatment. For example, electrically assisted NF membranes were designed to improve membrane desalination performance (e.g., enhanced $\mathrm{NaCl}$ rejection from $54 \%$ to $82 \%$ via increasing applied voltage from 0 to $2.5 \mathrm{~V}$ ) through finely tuned surface charge [139]. TFN membranes were also investigated to treat real brackish water [140].

NF process also has great flexibility to integrate with other separation technique to enhance the overall treatment efficiency (Fig. 7). For example, NF process was designed to couple with coagulation process to reduce membrane fouling propensity and improve desalination performance (Fig. 7(a)) [141-143]. Colloidal/organic fouling and scaling during NF would be successfully mitigated by the coagulation process. The integrated desalination system showed excellent sulfate removal and high rejection of divalent cations. Ion exchange could also be

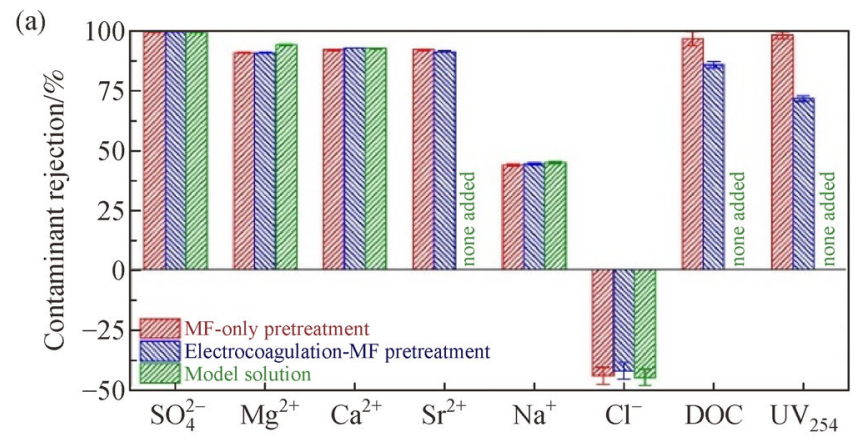

(b)

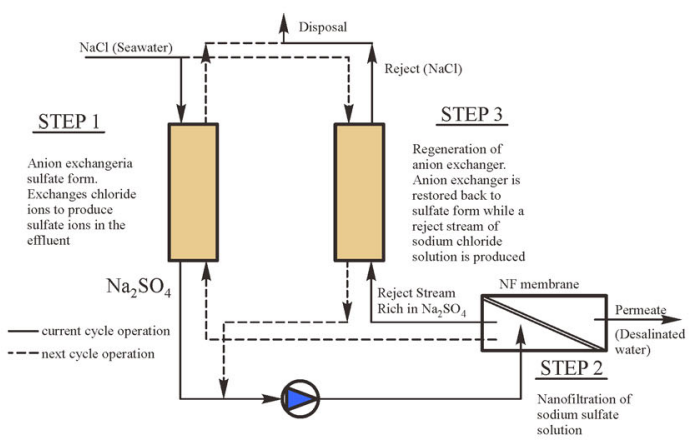

integrated with NF process for brackish water desalination (Fig. 7(b)). The results indicate the significant reduction on energy consumption by the hybrid ion exchange-NF process compared with RO treatment [144]. Moreover, the hybrid system could potentially treat hard brackish water via separately removing $\mathrm{Ca}^{2+}$ and $\mathrm{SO}_{4}{ }^{2-}$ through ion exchange and NF process, respectively. Meanwhile, the concentrate solution containing $\mathrm{NaCl}$ could be used to regenerate the ion exchange resins. Capacitive deionization (CDI) process has also been coupled with NF process to treat brackish water (Fig. 7(c)) [145]. The CDI-NF hybrid system could produce high-quality drinking water with a significantly reduced energy consumption compared to RO. Forward osmosis (FO) could also be combined NF to treat brackish water (Fig. 7(d)) [146]. Briefly, FO process used divalent salts solution (e.g., $\mathrm{Na}_{2} \mathrm{SO}_{4}$ or $\mathrm{MgSO}_{4}$ ) as draw solution to treat brackish water, following by the NF re-concentration of diluted draw solution and production of clean water.

\section{$7 \quad$ NF for point of use applications}

Conventional drinking water supply system consists of collection system, centralized treatment plant, and distribution system. After the treatment in plant, water may

(c)

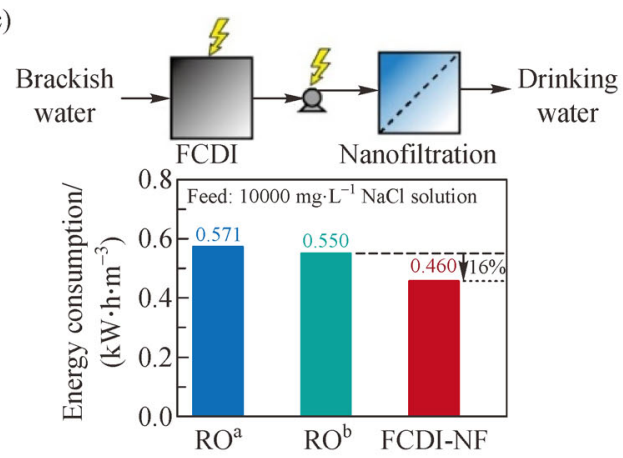

(d)

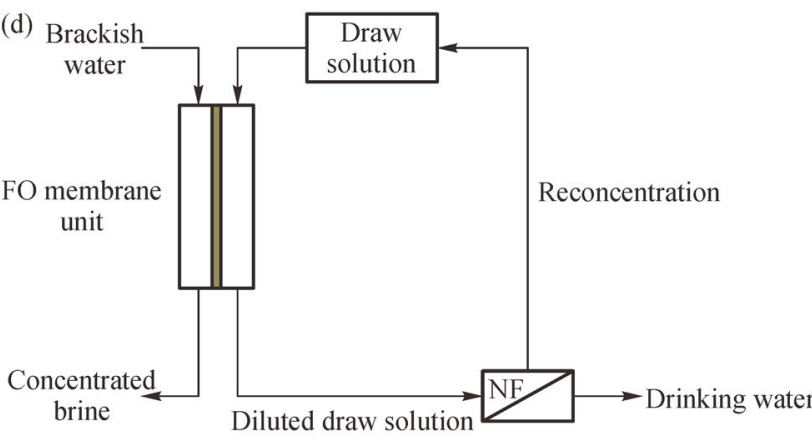

Fig. 7 (a) Removal of various ions and compounds from reservoir water using an integrated electrocoagulation-microfiltration-NF system. Reprinted with permission from ref. [143], copyright 2017, John Wiley \& Sons. (b) Illustration of an ion exchange-NF system for desalination. Reprinted with permission from ref. [144], copyright 2008, Elsevier BV. (c) An energy saving CDI-NF hybrid system for brackish water treatment. Reprinted with permission from ref. [145], copyright 2017, Elsevier BV. (d) An FO-NF system for brackish water treatment. Reprinted with permission from ref. [146], copyright 2012, John Wiley \& Sons. 
also be polluted by pipe deterioration, pipe leakage, and microbial contamination in water distribution system [147]. Moreover, the occurrence of DBPs in the drinking water distribution system also poses great challenges to the safety of end users $[148,149]$. The mismatch between the increasing concerns on drinking water safety and increasing demand on high-quality drinking water is calling for effective strategies to produce reliable and safe water for end users.

One promising strategy is point of use drinking water treatment, which employs water purification systems at the end of the drinking water system (e.g., water tap, Fig. 8) [150]. As a decentralized water purification device, the point-of-use purifier should meet the criteria of low maintenance, ease of automation, and chemical free. NF cannot only well meet these requirements, but also shows good efficiencies for pollutant removal [151,152]. For example, a recent study reported the application of NF for treating disinfected drinking water [153], which should be directly send to the end users via distribution system. The results showed that the water quality was significantly improved via reducing dissolved organic carbon, total dissolved solids, and DBPs in the permeate water. Furthermore, NF-based point of use water purification system has great flexibility to integrate with other treatment methods to ensure the quality of product water. For instance, a NF system combined with granularfiltration/granular activated carbon sorption could substantially improve the quality of tap waters [154]. Point of use NF filter also benefits to the drinking water supply in vehicles. For example, NF-based locomotive drinking water purification could be realized at low pressure of $0.3-$ $0.5 \mathrm{MPa}$ with varying feed water quality and environmental conditions. The removal efficiency of excessive $\mathrm{MgSO}_{4}$ by the point of use system could reach $97 \%-98 \%$ [155]. In addition, NF-based point of use drinking water treatment systems are beneficial for rural areas and developing countries/regions thanks to its small footprint and easy maintenance [150]. The technology showed promising results for removing hardness, fluoride, dissolved organic carbon, and viruses, allowing people to obtain reliable drinking water.

\section{Outlook and perspectives}

This review comprehensively summarized the progress of NF-based technology for drinking water production under different application scenarios. With the development of novel membrane materials (e.g., carbon-based materials [156], 2D materials [58,157], metal organic frameworks [57], and covalent organic frameworks [158]) and improvement on membrane fabrication technique, NF membranes can achieve enhanced drinking water production and quality together with reduced energy consumption. Although NF enjoys significant advantages on membrane-based drinking water treatment, there are still several challenges including fouling, chemical stability, integrity, and selectivity, which need to be more effectively addressed in the future.

\subsection{Fouling control}

Fouling is a major obstacle for membrane-based drinking water treatment [159-161]. Specifically, severe fouling could not only increase membrane hydraulic resistance (i.e., increase operational pressure) but also decreased solutes rejection [162-164]. Surface coating, such as polydopamine $[165,166]$ and polyvinyl alcohol [167] can effectively enhance membrane surface hydrophilicity, hence increasing membrane antifouling properties toward hydrophobic foulants, such as bovine serum albumin. Nevertheless, coating an additional layer onto a membrane could adversely result in decrease membrane permeance

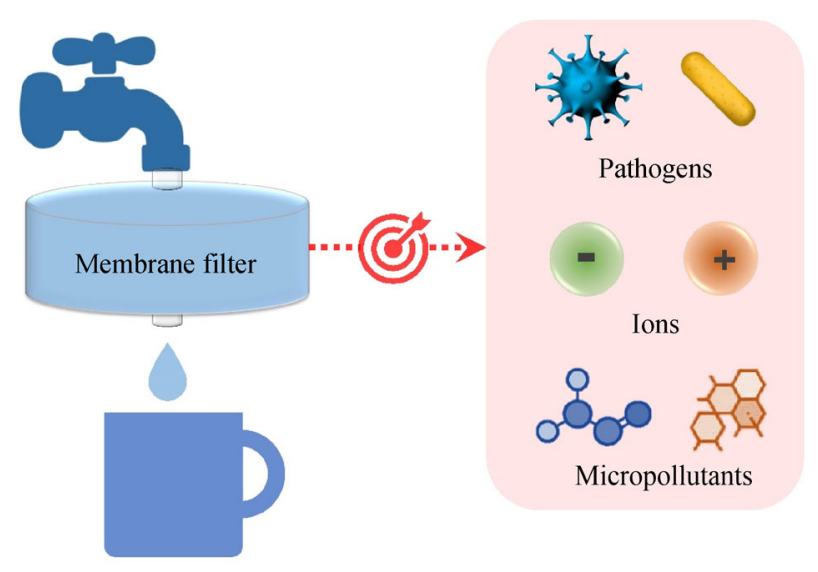

Fig. 8 Schematic illustration of a membrane-based tap water filter for point of use drinking water production. The filter shall able to remove various contaminants such as pathogens, dissolved ions, and micropollutants from drinking water source and thus safeguard product water quality. 
due to the increased hydraulic resistance according to the resistance-in-series model [168]. Another effective strategy for membrane fouling control is to tune membrane surface roughness. Traditional wisdom believes a membrane with a smoother surface is less prone to fouling $[169,170]$. In contrast, a recent highlight some compelling evidence that a membrane with a rougher surface may less be fouled [171]. Such controversy may be related to the characteristic length of roughness and calls for more future studies to resolve the relationship membrane fouling behavior and its surface roughness. In addition to organic and inorganic fouling, microbial fouling (i.e., biofouling) issues can be potentially mitigated by incorporating antimicrobial agents in membranes (e.g., silver nanoparticles [172] and graphene oxide [173]) and engineering the biofilm formed on the membrane surface [174].

\subsection{Chlorine stability}

Another important dilemma of the TFC NF membrane is its vulnerability to chlorine, which is often incorporated in the drinking water treatment process for disinfection purpose [175]. In principle, polyamide could be chemically degraded when encountering chlorine species, resulting in reduced membrane separation performance $[176,177]$. Many efforts have been undertaken to design membranes with enhanced anti-chlorine properties, such as synthesizing novel monomer [40] and membrane surface modification $[167,178]$. For instance, polyester chemistry shows improved chlorine resistance compared to polyamide, which has been extensively studied and utilized as a membrane rejection layer $[40,41]$. Nevertheless, to fully unleash the potential of the polyester-based membrane, the chemical and mechanical stability of the polyester chemistry needs further systematic investigation, such as the $\mathrm{pH}$ tolerance and long-term filtration stability under cross-flow conditions.

\subsection{Integrity}

Membrane integrity is also a critical aspect influencing membrane separation performance, especially for the rejection of pathogens. However, the integrity of the membrane module is not the primary focus for manufacturers because NF module is primarily designed for total dissolved solids removal. To better remove pathogen in $\mathrm{NF}$, the integrity of NF could be improved by optimizing manufacturing process, and sensitive methods should be established for integrity monitoring. As discussed in Section 5.2, NF membranes may contain intrinsically nanosized defects [132] which would partially contribute to the unsatisfactory rejection of virus (i.e., $\sim 25 \mathrm{~nm}$ in size, $>5-\log$ removal) [129]. Accordingly, many strategies have been proposed to minimize defect regions in the rejection layer, such as regulating IP reaction by the addition of surfactant in aqueous amine solution [179], the incorporation of an inhibitor to control monomer's diffusion [180], and the inclusion of an additional interlayer between the substrate and polyamide rejection layer [26]. Nevertheless, future studies need to systematically address the formation mechanisms and healing strategies to minimize the effects of membrane integrity loss and thus improve membrane separation efficiency.

\subsection{Selectivity}

Based on the above discussion, a key priority for NF-based drinking water treatment is to effectively remove organic micropollutants and heavy metals with critical concerns, while the removal of salt ions may not be over emphasized in most cases. The high rejection of salt ions (e.g., $\mathrm{Ca}^{2+}$, $\mathrm{Mg}^{2+}$, and $\mathrm{SO}_{4}{ }^{2-}$ ) by a NF membrane may not only lead to the severe concentration polarization and further scaling issue, but also compromise the health values of produced drinking water. Instead, a NF membrane with a high selectivity against the targeted pollutants and a relatively low removal of salt is preferred. The selectivity of NF membrane can be tailored through suppressing the passage of targeted solutes and/or accelerating water transport across the membrane. For example, membrane surface properties (e.g., charge [181], pore size/distribution [15], and hydrophilicity [121]) can be tuned through surface modification to reduce the partition of pollutants into membrane thereby enhancing their rejections. Introduction of additional components (e.g., nanofillers and interlayer) into the membrane matrix (e.g., TFN and TFNi membranes) could often facilitate water transport across the membrane because of the creation of additional water channels and/or reduced membrane thickness [24,26]. Nevertheless, a systematic understanding on the selectivity of NF membranes is still lack in the existing literature. Following research efforts are needed to build a concise and effective framework to guide the optimization of NF membranes targeting for highly selective removal of pollutants in drinking water treatment.

Acknowledgements This work is supported by Senior Research Fellow Scheme of Research Grant Council (Grant No. SRFS2021-7S04) in Hong Kong and Seed Fund for Translational and Applied Research at The University of Hong Kong, China (Grant No. 104006007).

\section{References}

1. Johnson N, Revenga C, Echeverria J. Managing water for people and nature. Science, 2001, 292(5519): 1071-1072

2. Mekonnen M M, Hoekstra A Y. Four billion people facing severe water scarcity. Science Advances, 2016, 2(2): e1500323

3. United Nations. Clean water and sanitation, sustainable development goals. United Nations website, 2015

4. Shannon M A, Bohn P W, Elimelech M, Georgiadis J G, Mariñas B J, Mayes A M. Science and technology for water purification in the coming decades. Nature, 2008, 452(7185): 301-310 
5. Qasim M, Badrelzaman M, Darwish N N, Darwish N A, Hilal N. Reverse osmosis desalination: a state-of-the-art review. Desalination, 2019, 459: 59-104

6. Fane A, Tang C, Wang R. Membrane technology for water: microfiltration, ultrafiltration, nanofiltration, and reverse osmosis. Treatise on Water Science. Oxford: Academic Press, 2011

7. Schäfer A, Fane A G, Waite T D. Nanofiltration: Principles and Applications. Amsterdam: Elsevier, 2005

8. Jye L W, Ismail A F. Nanofiltration Membranes: Synthesis, Characterization, and Applications. 1st ed. Florida: CRC Press, 2016, 15-30

9. Lau W J, Ismail A F, Misdan N, Kassim M A. A recent progress in thin film composite membrane: a review. Desalination, 2012, 287 : 190-199

10. Xu G R, Xu J M, Feng H J, Zhao H L, Wu S B. Tailoring structures and performance of polyamide thin film composite (PA-TFC) desalination membranes via sublayers adjustment: a review. Desalination, 2017, 417: 19-35

11. Gohil J M, Ray P. Ray P. A review on semi-aromatic polyamide TFC membranes prepared by interfacial polymerization: potential for water treatment and desalination. Separation and Purification Technology, 2017, 181: 159-182

12. Zhang R, Su Y, Zhao X, Li Y, Zhao J, Jiang Z. A novel positively charged composite nanofiltration membrane prepared by bioinspired adhesion of polydopamine and surface grafting of poly (ethylene imine). Journal of Membrane Science, 2014, 470: 9-17

13. Ng L Y, Mohammad A W, Ng C Y. A review on nanofiltration membrane fabrication and modification using polyelectrolytes: effective ways to develop membrane selective barriers and rejection capability. Advances in Colloid and Interface Science, 2013, 197-198: 85-107

14. Li C, Sun W, Lu Z, Ao X, Li S. Ceramic nanocomposite membranes and membrane fouling: a review. Water Research, 2020, 175: 115674

15. Zhao Y, Tong X, Chen Y. Fit-for-purpose design of nanofiltration membranes for simultaneous nutrient recovery and micropollutant removal. Environmental Science \& Technology, 2021, 55(5): $3352-3361$

16. World Health Organization. Guidelines for Drinking-Water Quality. 4th ed. Geneva: World Health Organization, 2011, 117230

17. Van der Bruggen B, Mänttäri $M$, Nyström M. Drawbacks of applying nanofiltration and how to avoid them: a review. Separation and Purification Technology, 2008, 63(2): 251-263

18. Shon H K, Phuntsho S, Chaudhary D S, Vigneswaran S, Cho J. Nanofiltration for water and wastewater treatment: a mini review. Drinking Water Engineering and Science, 2013, 6(1): 47-53

19. Mohammad A W, Teow Y H, Ang W L, Chung Y T, OatleyRadcliffe D L, Hilal N. Nanofiltration membranes review: recent advances and future prospects. Desalination, 2015, 356: 226-254

20. Tul Muntha S, Kausar A, Siddiq M. Advances in polymeric nanofiltration membrane: a review. Polymer-Plastics Technology and Engineering, 2017, 56(8): 841-856

21. Zhao $\mathrm{Y}$, Tong $\mathrm{T}$, Wang $\mathrm{X}$, Lin $\mathrm{S}$, Reid $\mathrm{E} \mathrm{M}$, Chen $\mathrm{Y}$. Differentiating solutes with precise nanofiltration for next generation environmental separations: a review. Environmental Science
\& Technology, 2021, 55(3): 1359-1376

22. Yang Z, Guo H, Tang C Y. The upper bound of thin-film composite (TFC) polyamide membranes for desalination. Journal of Membrane Science, 2019, 590: 117297

23. Lau W J, Gray S, Matsuura T, Emadzadeh D, Paul Chen J, Ismail A F. A review on polyamide thin film nanocomposite (TFN) membranes: history, applications, challenges and approaches. Water Research, 2015, 80: 306-324

24. Yang Z, Guo H, Yao Z K, Mei Y, Tang C Y. Hydrophilic silver nanoparticles induce selective nanochannels in thin film nanocomposite polyamide membranes. Environmental Science \& Technology, 2019, 53(9): 5301-5308

25. Zhang T, Li Z, Wang W, Wang Y, Gao B, Wang Z. Enhanced antifouling and antimicrobial thin film nanocomposite membranes with incorporation of palygorskite/titanium dioxide hybrid material. Journal of Colloid and Interface Science, 2019, 537: 1-10

26. Yang Z, Sun P F, Li X, Gan B, Wang L, Song X, Park H D, Tang C Y. A critical review on thin-film nanocomposite membranes with interlayered structure: mechanisms, recent developments, and environmental applications. Environmental Science \& Technology, 2020, 54(24): 15563-15583

27. Wang J J, Yang H C, Wu M B, Zhang X, Xu Z K. Nanofiltration membranes with cellulose nanocrystals as an interlayer for unprecedented performance. Journal of Materials Chemistry. A, Materials for Energy and Sustainability, 2017, 5(31): 16289-16295

28. Karan S, Jiang Z, Livingston A G. Sub-10 nm polyamide nanofilms with ultrafast solvent transport for molecular separation. Science, 2015, 348(6241): 1347-1351

29. Yang Z, Wang F, Guo H, Peng L E, Ma X H, Song X H, Wang Z, Tang C Y. Mechanistic insights into the role of polydopamine interlayer toward improved separation performance of polyamide nanofiltration membranes. Environmental Science \& Technology, 2020, 54(18): 11611-11621

30. Pacheco F A, Pinnau I, Reinhard M, Leckie J O. Characterization of isolated polyamide thin films of RO and NF membranes using novel TEM techniques. Journal of Membrane Science, 2010, 358(1): 51-59

31. Guo H, Yao Z, Yang Z, Ma X, Wang J, Tang C Y. A one-step rapid assembly of thin film coating using green coordination complexes for enhanced removal of trace organic contaminants by membranes. Environmental Science \& Technology, 2017, 51(21): 12638-12643

32. Yang Z, Ma X H, Tang C Y. Recent development of novel membranes for desalination. Desalination, 2018, 434: 37-59

33. Zhang H, He Q, Luo J, Wan Y, Darling S B. Sharpening nanofiltration: strategies for enhanced membrane selectivity. ACS Applied Materials \& Interfaces, 2020, 12(36): 39948-39966

34. Raaijmakers M J, Benes N E. Current trends in interfacial polymerization chemistry. Progress in Polymer Science, 2016, 63: $86-142$

35. Thakur V K, Voicu S I. Recent advances in cellulose and chitosan based membranes for water purification: a concise review. Carbohydrate Polymers, 2016, 146: 148-165

36. Narbaitz R M, Rana D, Dang H T, Morrissette J, Matsuura T, Jasim S Y, Tabe S, Yang P. Pharmaceutical and personal care products removal from drinking water by modified cellulose acetate 
membrane: field testing. Chemical Engineering Journal, 2013, 225 : 848-856

37. Lalia B S, Kochkodan V, Hashaikeh R, Hilal N. A review on membrane fabrication: structure, properties and performance relationship. Desalination, 2013, 326: 77-95

38. Van der Bruggen B, Daems B, Wilms D, Vandecasteele C. Mechanisms of retention and flux decline for the nanofiltration of dye baths from the textile industry. Separation and Purification Technology, 2001, 22-23(1-2): 519-528

39. Zeng C, Tanaka S, Suzuki Y, Fujii S. Impact of feed water $\mathrm{pH}$ and membrane material on nanofiltration of perfluorohexanoic acid in aqueous solution. Chemosphere, 2017, 183: 599-604

40. Yao Y, Zhang P, Jiang C, DuChanois R M, Zhang X, Elimelech M. High performance polyester reverse osmosis desalination membrane with chlorine resistance. Nature Sustainability, 2021, 4(2): 138-146

41. Zheng J, Liu Y, Zhu J, Jin P, Croes T, Volodine A, Yuan S, Van der Bruggen B. Sugar-based membranes for nanofiltration. Journal of Membrane Science, 2021, 619: 118786

42. Soroko I, Bhole Y, Livingston A G. Environmentally friendly route for the preparation of solvent resistant polyimide nanofiltration membranes. Green Chemistry, 2011, 13(1): 162-168

43. Sairam M, Loh X, Bhole Y, Sereewatthanawut I, Li K, Bismarck A, Steinke J, Livingston A. Spiral-wound polyaniline membrane modules for organic solvent nanofiltration (OSN). Journal of Membrane Science, 2010, 349(1-2): 123-129

44. Wang K, Xu L, Li K, Liu L, Zhang Y, Wang J. Development of polyaniline conductive membrane for electrically enhanced membrane fouling mitigation. Journal of Membrane Science, 2019, 570: 371-379

45. Cheng W, Liu C, Tong T, Epsztein R, Sun M, Verduzco R, Ma J, Elimelech M. Selective removal of divalent cations by polyelectrolyte multilayer nanofiltration membrane: role of polyelectrolyte charge, ion size, and ionic strength. Journal of Membrane Science, 2018, 559: 98-106

46. Yang S, Wang J, Fang L, Lin H, Liu F, Tang C Y. Electrosprayed polyamide nanofiltration membrane with intercalated structure for controllable structure manipulation and enhanced separation performance. Journal of Membrane Science, 2020, 602: 117971

47. Mazzoni C, Orlandini F, Bandini S. Role of electrolyte type on $\mathrm{TiO}_{2}-\mathrm{ZrO}_{2}$ nanofiltration membranes performances. Desalination, 2009, 240(1-3): 227-235

48. Nishihora R K, Rachadel P L, Quadri M G N, Hotza D. Manufacturing porous ceramic materials by tape casting-a review. Journal of the European Ceramic Society, 2018, 38(4): 988-1001

49. Xing W H. Ceramic Membranes, in Membrane-Based Separations in Metallurgy. 1st ed. Amsterdam: Elsevier, 2017, 357-370

50. Samaei S M, Gato-Trinidad S, Altaee A. The application of pressure-driven ceramic membrane technology for the treatment of industrial wastewaters - a review. Separation and Purification Technology, 2018, 200: 198-220

51. Zhu J, Hou J, Uliana A, Zhang Y, Tian M, Van der Bruggen B. The rapid emergence of two-dimensional nanomaterials for highperformance separation membranes. Journal of Materials Chemistry. A, Materials for Energy and Sustainability, 2018, 6(9): 3773
3792

52. Ding L, Li L, Liu Y, Wu Y, Lu Z, Deng J, Wei Y, Caro J, Wang H. Effective ion sieving with $\mathrm{Ti}_{3} \mathrm{C}_{2} \mathrm{~T}_{\mathrm{x}}$ mxene membranes for production of drinking water from seawater. Nature Sustainability, 2020, 3(4): 296-302

53. $\mathrm{Hu} \mathrm{M}$, Mi B. Enabling graphene oxide nanosheets as water separation membranes. Environmental Science \& Technology, 2013, 47(8): 3715-3723

54. Liu C, Jiang Y, Nalaparaju A, Jiang J, Huang A. Post-synthesis of a covalent organic framework nanofiltration membrane for highly efficient water treatment. Journal of Materials Chemistry. A, Materials for Energy and Sustainability, 2019, 7(42): 24205-24210

55. Deng J, Lu Z, Ding L, Li Z K, Wei Y, Caro J, Wang H. Fast electrophoretic preparation of large-area two-dimensional titanium carbide membranes for ion sieving. Chemical Engineering Journal, 2021, 408: 127806

56. Asif M B, Zhang Z. Ceramic membrane technology for water and wastewater treatment: a critical review of performance, full-scale applications, membrane fouling and prospects. Chemical Engineering Journal, 2021, 418: 129481

57. Li X, Liu Y, Wang J, Gascon J, Li J, Van der Bruggen B. Metalorganic frameworks based membranes for liquid separation. Chemical Society Reviews, 2017, 46(23): 7124-7144

58. Al-Hamadani Y A J, Jun B M, Yoon M, Taheri-Qazvini N, Snyder S A, Jang M, Heo J, Yoon Y. Applications of mxene-based membranes in water purification: a review. Chemosphere, 2020, 254: 126821

59. Shao S, Qu F, Liang H, Chang H, Yu H, Li G. A pilot-scale study of a powdered activated carbon-membrane bioreactor for the treatment of water with a high concentration of ammonia. Environmental Science. Water Research \& Technology, 2016, 2 (1): 125-133

60. Schwarzenbach R P, Escher B I, Fenner K, Hofstetter T B, Johnson C A, Von Gunten U, Wehrli B. The challenge of micropollutants in aquatic systems. Science, 2006, 313(5790): 1072-1077

61. Bei E, Wu X, Qiu Y, Chen C, Zhang X. A tale of two water supplies in China: finding practical solutions to urban and rural water supply problems. Accounts of Chemical Research, 2019, 52 (4): $867-875$

62. Crittenden J C, Trussell R R, Hand D W, Howe K J, Tchobanoglous G. Mwh's Water Treatment: Principles and Design. 3rd ed. New Jersey: John Wiley \& Sons, 2012, 165-224

63. Cyna B, Chagneau G, Bablon G, Tanghe N. Two years of nanofiltration at the méry-sur-oise plant, france. Desalination, 2002, 147(1): 69-75

64. Davis M L, Cornwell D A. Introduction to Environmental Engineering. 5th ed. New York: McGraw-Hill, 2012, 250-387

65. Huang H, Schwab K, Jacangelo J G. Pretreatment for low pressure membranes in water treatment: a review. Environmental Science \& Technology, 2009, 43(9): 3011-3019

66. Shao S, Liang H, Qu F, Yu H, Li K, Li G. Fluorescent natural organic matter fractions responsible for ultrafiltration membrane fouling: identification by adsorption pretreatment coupled with parallel factor analysis of excitation-emission matrices. Journal of Membrane Science, 2014, 464: 33-42

67. Liao B, Chang C Y, Chang C C, Liu T W. Performance of a 
270000 CMD integrated membrane system for water supply in Taiwan. Desalination and Water Treatment, 2011, 32(1-3): 411421

68. Nieuwenhuijsen M J, Toledano M B, Eaton N E, Fawell J, Elliott P. Chlorination disinfection byproducts in water and their association with adverse reproductive outcomes: a review. Occupational and Environmental Medicine, 2000, 57(2): 73-85

69. Singer P C. Formation and control of disinfection by-products in drinking water. Journal of Environmental Engineering, 1994, 120 (4): 727-744

70. Zazouli M A, Kalankesh L R. Removal of precursors and disinfection by-products (DBPs) by membrane filtration from water: a review. Journal of Environmental Health Science \& Engineering, 2017, 15(1): 1-10

71. Ersan M S, Ladner D A, Karanfil T. The control of $\mathrm{N}$ nitrosodimethylamine, halonitromethane, and trihalomethane precursors by nanofiltration. Water Research, 2016, 105: 274-281

72. Peltier S, Cotte M, Gatel D, Herremans L, Cavard J. Nanofiltration: improvements of water quality in a large distribution system. Water Science and Technology: Water Supply, 2003, 3(1-2): 193-200

73. Lin D, Liang H, Li G. Factors affecting the removal of bromate and bromide in water by nanofiltration. Environmental Science and Pollution Research International, 2020, 27(20): 24639-24649

74. Chellam S. Effects of nanofiltration on trihalomethane and haloacetic acid precursor removal and speciation in waters containing low concentrations of bromide ion. Environmental Science \& Technology, 2000, 34(9): 1813-1820

75. Ohkouchi Y, Yata Y, Bun R, Itoh S. Chlorine requirement for biologically stable drinking water after nanofiltration. Water Science and Technology: Water Supply, 2014, 14(3): 405-413

76. Niu B, Loaiciga H A, Wang Z, Zhan F B, Hong S. Twenty years of global groundwater research: a science citation index expandedbased bibliometric survey (1993-2012). Journal of Hydrology (Amsterdam), 2014, 519: 966-975

77. Wang Y, Ju L, Xu F, Tian L, Jia R, Song W, Li Y, Liu B. Effect of a nanofiltration combined process on the treatment of high-hardness and micropolluted water. Environmental Research, 2020, 182: 109063

78. Hadley P W, Newell C J. Groundwater remediation: the next 30 years. Ground Water, 2012, 50(5): 669-678

79. Sen M, Manna A, Pal P. Removal of arsenic from contaminated groundwater by membrane-integrated hybrid treatment system. Journal of Membrane Science, 2010, 354(1-2): 108-113

80. Lu D, Sha S, Luo J, Huang Z, Jackie X Z. Treatment train approaches for the remediation of per-and polyfluoroalkyl substances (PFAS): a critical review. Journal of Hazardous Materials, 2020, 386: 121963

81. Schaep J, Van der Bruggen B, Uytterhoeven S, Croux R, Vandecasteele C, Wilms D, Van Houtte E, Vanlerberghe F. Removal of hardness from groundwater by nanofiltration. Desalination, 1998, 119(1-3): 295-301

82. Van der Bruggen B, Vandecasteele C. Removal of pollutants from surface water and groundwater by nanofiltration: overview of possible applications in the drinking water industry. Environmental Pollution, 2003, 122(3): 435-445

83. Krieg H, Modise S, Keizer K, Neomagus H. Salt rejection in nanofiltration for single and binary salt mixtures in view of sulphate removal. Desalination, 2005, 171(2): 205-215

84. Tu K L, Nghiem L D, Chivas A R. Coupling effects of feed solution $\mathrm{pH}$ and ionic strength on the rejection of boron by NF/RO membranes. Chemical Engineering Journal, 2011, 168(2): 700706

85. Boo C, Wang Y, Zucker I, Choo Y, Osuji C O, Elimelech M. High performance nanofiltration membrane for effective removal of perfluoroalkyl substances at high water recovery. Environmental Science \& Technology, 2018, 52(13): 7279-7288

86. Smedley P L, Kinniburgh D G. A review of the source, behaviour and distribution of arsenic in natural waters. Applied Geochemistry, 2002, 17(5): 517-568

87. Straif K, Benbrahim-Tallaa L, Baan R, Grosse Y, Secretan B, El Ghissassi F, Bouvard V, Guha N, Freeman C, Galichet L, Cogliano V. A review of human carcinogens - part C: metals, arsenic, dusts, and fibres. Lancet. Oncology, 2009, 10(5): 453-454

88. Figoli A, Fuoco I, Apollaro C, Chabane M, Mancuso R, Gabriele B, De Rosa R, Vespasiano G, Barca D, Criscuoli A. Arseniccontaminated groundwaters remediation by nanofiltration. Separation and Purification Technology, 2020, 238: 116461

89. Siddique T, Dutta N K, Roy Choudhury N. Nanofiltration for arsenic removal: challenges, recent developments, and perspectives. Nanomaterials (Basel, Switzerland), 2020, 10(7): 1323

90. Košutić K, Furač L, Sipos L, Kunst B. Removal of arsenic and pesticides from drinking water by nanofiltration membranes. Separation and Purification Technology, 2005, 42(2): 137-144

91. Pal P, Chakrabortty S, Linnanen L. A nanofiltration-coagulation integrated system for separation and stabilization of arsenic from groundwater. Science of the Total Environment, 2014, 476: 601610

92. Chang F F, Liu W J, Wang X M. Comparison of polyamide nanofiltration and low-pressure reverse osmosis membranes on As (III) rejection under various operational conditions. Desalination, 2014, 334(1): 10-16

93. Boussouga Y A, Frey H, Schäfer A I. Removal of arsenic(V) by nanofiltration: impact of water salinity, $\mathrm{pH}$ and organic matter. Journal of Membrane Science, 2021, 618: 118631

94. Zhao C, Zhang J, He G, Wang T, Hou D, Luan Z. Perfluorooctane sulfonate removal by nanofiltration membrane the role of calcium ions. Chemical Engineering Journal, 2013, 233: 224-232

95. Xiao F, Simcik M F, Halbach T R, Gulliver J S. Perfluorooctane sulfonate (PFOS) and perfluorooctanoate (PFOA) in soils and groundwater of a us metropolitan area: migration and implications for human exposure. Water Research, 2015, 72: 64-74

96. Barzen-Hanson K A, Roberts S C, Choyke S, Oetjen K, McAlees A, Riddell N, McCrindle R, Ferguson P L, Higgins C P, Field J A. Discovery of 40 classes of per- and polyfluoroalkyl substances in historical aqueous film-forming foams (AFFFs) and AFFFimpacted groundwater. Environmental Science \& Technology, 2017, 51(4): 2047-2057

97. MacInnis J J, Lehnherr I, Muir D C, St. Pierre K A, St. Louis V L, Spencer C, De Silva A O. Fate and transport of perfluoroalkyl substances from snowpacks into a lake in the high arctic of Canada. Environmental Science \& Technology, 2019, 53(18): 1075310762 
98. Wang F, Liu W, Jin Y, Dai J, Yu W, Liu X, Liu L. Transcriptional effects of prenatal and neonatal exposure to pfos in developing rat brain. Environmental Science \& Technology, 2010, 44(5): 18471853

99. Briels N, Ciesielski T M, Herzke D, Jaspers V L. Developmental toxicity of perfluorooctanesulfonate (PFOS) and its chlorinated polyfluoroalkyl ether sulfonate alternative F-53B in the domestic chicken. Environmental Science \& Technology, 2018, 52(21): 12859-12867

100. Wang T, Zhao C, Li P, Li Y, Wang J. Fabrication of novel poly $(m$ phenylene isophthalamide) hollow fiber nanofiltration membrane for effective removal of trace amount perfluorooctane sulfonate from water. Journal of Membrane Science, 2015, 477: 74-85

101. Franke V, McCleaf P, Lindegren K, Ahrens L. Efficient removal of per-and polyfluoroalkyl substances (PFASS) in drinking water treatment: nanofiltration combined with active carbon or anion exchange. Environmental Science. Water Research \& Technology, 2019, 5(11): 1836-1843

102. Zhao C, Zhang T, Hu G, Ma J, Song R, Li J. Efficient removal of perfluorooctane sulphonate by nanofiltration: insights into the effect and mechanism of coexisting inorganic ions and humic acid. Journal of Membrane Science, 2020, 610: 118176

103. Guo H, Zhang J, Peng L E, Li X, Chen Y, Yao Z, Fan Y, Shih K, Tang C Y. High-efficiency capture and recovery of anionic perfluoroalkyl substances from water using PVA/PDDA nanofibrous membranes with near-zero energy consumption. Environmental Science \& Technology Letters, 2021, 8(4): 350-355

104. Werber J R, Deshmukh A, Elimelech M. The critical need for increased selectivity, not increased water permeability, for desalination membranes. Environmental Science \& Technology Letters, 2016, 3(4): 112-120

105. Tang C Y, Yang Z, Guo H, Wen J J, Nghiem L D, Cornelissen E. Potable water reuse through advanced membrane technology. Environmental Science \& Technology, 2018, 52(18): 1021510223

106. Public Utilities Board (PUB) of Singapore. Four national taps. PUB webisite, 2015

107. Orange County Water District (OCWD). Water factory 21. OCWD website, 2000

108. Public Utilities Board (PUB) of Singapore. Newater. PUB website, 2003

109. Yangali-Quintanilla V, Maeng S K, Fujioka T, Kennedy M, Amy G. Proposing nanofiltration as acceptable barrier for organic contaminants in water reuse. Journal of Membrane Science, 2010, 362(1): 334-345

110. Tang C, Chen V. Nanofiltration of textile wastewater for water reuse. Desalination, 2002, 143(1): 11-20

111. Riera-Torres M, Gutiérrez-Bouzán C, Crespi M. Combination of coagulation-flocculation and nanofiltration techniques for dye removal and water reuse in textile effluents. Desalination, 2010, 252(1): 53-59

112. Taheran M, Brar S K, Verma M, Surampalli R Y, Zhang T C, Valero J R. Membrane processes for removal of pharmaceutically active compounds (PHACs) from water and wastewaters. Science of the Total Environment, 2016, 547: 60-77

113. Loos R, Carvalho R, Antonio D C, Comero S, Locoro G, Tavazzi
S, Paracchini B, Ghiani M, Lettieri T, Blaha L, et al. Eu-wide monitoring survey on emerging polar organic contaminants in wastewater treatment plant effluents. Water Research, 2013, 47 (17): 6475-6487

114. Garcia-Ivars J, Martella L, Massella M, Carbonell-Alcaina C, Alcaina-Miranda M I, Iborra-Clar M I. Nanofiltration as tertiary treatment method for removing trace pharmaceutically active compounds in wastewater from wastewater treatment plants. Water Research, 2017, 125: 360-373

115. Kim S, Chu K H, Al-Hamadani Y A J, Park C M, Jang M, Kim D $\mathrm{H}$, Yu M, Heo J, Yoon Y. Removal of contaminants of emerging concern by membranes in water and wastewater: a review. Chemical Engineering Journal, 2018, 335: 896-914

116. Bellona C, Drewes J E, Xu P, Amy G. Factors affecting the rejection of organic solutes during NF/RO treatment - a literature review. Water Research, 2004, 38(12): 2795-2809

117. Warsinger D M, Chakraborty S, Tow E W, Plumlee M H, Bellona C, Loutatidou S, Karimi L, Mikelonis A M, Achilli A, Ghassemi A, et al. A review of polymeric membranes and processes for potable water reuse. Progress in Polymer Science, 2018, 81: 209-237

118. Guo H, Peng L E, Yao Z, Yang Z, Ma X, Tang C Y. Nonpolyamide based nanofiltration membranes using green metalorganic coordination complexes: implications for the removal of trace organic contaminants. Environmental Science \& Technology, 2019, 53(5): 2688-2694

119. Steinle-Darling E, Reinhard M. Nanofiltration for trace organic contaminant removal: structure, solution, and membrane fouling effects on the rejection of perfluorochemicals. Environmental Science \& Technology, 2008, 42(14): 5292-5297

120. Dai R, Wang X, Tang C Y, Wang Z. Dually charged MOF-based thin-film nanocomposite nanofiltration membrane for enhanced removal of charged pharmaceutically active compounds. Environmental Science \& Technology, 2020, 54(12): 7619-7628

121. Guo H, Deng Y, Tao Z, Yao Z, Wang J, Lin C, Zhang T, Zhu B, Tang C Y. Does hydrophilic polydopamine coating enhance membrane rejection of hydrophobic endocrine-disrupting compounds? Environmental Science \& Technology Letters, 2016, 3(9): $332-338$

122. Wijmans J G, Baker R W. The solution-diffusion model: a review. Journal of Membrane Science, 1995, 107(1): 1-21

123. Nghiem L D, Schäfer A I, Elimelech M. Removal of natural hormones by nanofiltration membranes: measurement, modeling, and mechanisms. Environmental Science \& Technology, 2004, 38 (6): 1888-1896

124. Fujioka T, Khan S J, McDonald J A, Nghiem L D. Nanofiltration of trace organic chemicals: a comparison between ceramic and polymeric membranes. Separation and Purification Technology, 2014, 136: 258-264

125. Dai R, Guo H, Tang C Y, Chen M, Li J, Wang Z. Hydrophilic selective nanochannels created by metal organic frameworks in nanofiltration membranes enhance rejection of hydrophobic endocrine-disrupting compounds. Environmental Science \& Technology, 2019, 53(23): 13776-13783

126. Yang Z, Zhou Z, Guo H, Yao Z, Ma X H, Song X, Feng S P, Tang C Y. Tannic acid $/ \mathrm{Fe}^{3+}$ nanoscaffold for interfacial polymerization: toward enhanced nanofiltration performance. Environmental 
Science \& Technology, 2018, 52(16): 9341-9349

127. Medema G, Heijnen L, Elsinga G, Italiaander R, Brouwer A. Presence of sars-coronavirus-2 RNA in sewage and correlation with reported COVID-19 prevalence in the early stage of the epidemic in the netherlands. Environmental Science \& Technology Letters, 2020, 7(7): 511-516

128. Pype M L, Lawrence M G, Keller J, Gernjak W. Reverse osmosis integrity monitoring in water reuse: the challenge to verify virus removal - a review. Water Research, 2016, 98: 384-395

129. Mi B, Eaton C L, Kim J H, Colvin C K, Lozier J C, Mariñas B J. Removal of biological and non-biological viral surrogates by spiral-wound reverse osmosis membrane elements with intact and compromised integrity. Water Research, 2004, 38(18): 3821-3832

130. Hornstra L M, Rodrigues da Silva T, Blankert B, Heijnen L, Beerendonk E, Cornelissen E R, Medema G. Monitoring the integrity of reverse osmosis membranes using novel indigenous freshwater viruses and bacteriophages. Environmental Science. Water Research \& Technology, 2019, 5(9): 1535-1544

131. Fujioka T, Boivin S. Assessing the passage of particles through polyamide reverse osmosis membranes. Separation and Purification Technology, 2019, 226: 8-12

132. Song X, Gan B, Qi S, Guo H, Tang C Y, Zhou Y, Gao C. Intrinsic nanoscale structure of thin film composite polyamide membranes: connectivity, defects, and structure-property correlation. Environmental Science \& Technology, 2020, 54(6): 3559-3569

133. Epsztein R, Shaulsky E, Dizge N, Warsinger D M, Elimelech M. Role of ionic charge density in Donnan exclusion of monovalent anions by nanofiltration. Environmental Science \& Technology, 2018, 52(7): 4108-4116

134. Lhassani A, Rumeau M, Benjelloun D, Pontie M. Selective demineralization of water by nanofiltration application to the defluorination of brackish water. Water Research, 2001, 35(13): 3260-3264

135. Santafé-Moros A, Gozálvez-Zafrilla J, Lora-García J. Performance of commercial nanofiltration membranes in the removal of nitrate ions. Desalination, 2005, 185(1-3): 281-287

136. Hilal N, Al-Zoubi H, Mohammad A, Darwish N. Nanofiltration of highly concentrated salt solutions up to seawater salinity. Desalination, 2005, 184(1-3): 315-326

137. Galanakis C M, Fountoulis G, Gekas V. Nanofiltration of brackish groundwater by using a polypiperazine membrane. Desalination, 2012, 286: 277-284

138. Walha K, Amar R B, Firdaous L, Quéméneur F, Jaouen P. Brackish groundwater treatment by nanofiltration, reverse osmosis and electrodialysis in Tunisia: performance and cost comparison. Desalination, 2007, 207(1-3): 95-106

139. Zhang H, Quan X, Fan X, Yi G, Chen S, Yu H, Chen Y. Improving ion rejection of conductive nanofiltration membrane through electrically enhanced surface charge density. Environmental Science \& Technology, 2018, 53(2): 868-877

140. Kotp Y H. High-flux TFN nanofiltration membranes incorporated with camphor- $\mathrm{Al}_{2} \mathrm{O}_{3}$ nanoparticles for brackish water desalination. Chemosphere, 2021, 265: 128999

141. Ang W L, Mohammad A W, Benamor A, Hilal N. Hybrid coagulation-NF membrane processes for brackish water treatment: effect of $\mathrm{pH}$ and salt/calcium concentration. Desalination, 2016,
390: $25-32$

142. Ang W L, Mohammad A W, Benamor A, Hilal N, Leo C P. Hybrid coagulation-NF membrane process for brackish water treatment: effect of antiscalant on water characteristics and membrane fouling. Desalination, 2016, 393: 144-150

143. Sari M A, Chellam S. Electrocoagulation process considerations during advanced pretreatment for brackish inland surface water desalination: nanofilter fouling control and permeate water quality. Desalination, 2017, 410: 66-76

144. Sarkar S, SenGupta A K. A new hybrid ion exchange-nanofiltration (HIX-NF) separation process for energy-efficient desalination: process concept and laboratory evaluation. Journal of Membrane Science, 2008, 324(1): 76-84

145. Choi S, Chang B, Kang J H, Diallo M S, Choi J W. Energyefficient hybrid FCDI-NF desalination process with tunable salt rejection and high water recovery. Journal of Membrane Science, 2017, 541: 580-586

146. Zhao S, Zou L, Mulcahy D. Brackish water desalination by a hybrid forward osmosis-nanofiltration system using divalent draw solute. Desalination, 2012, 284: 175-181

147. Cristo C D, Leopardi A. Pollution source identification of accidental contamination in water distribution networks. Journal of Water Resources Planning and Management, 2008, 134(2): 197-202

148. Wei J, Ye B, Wang W, Yang L, Tao J, Hang Z. Spatial and temporal evaluations of disinfection by-products in drinking water distribution systems in Beijing, China. Science of the Total Environment, 2010, 408(20): 4600-4606

149. Huang H, Zhu H, Gan W, Chen X, Yang X. Occurrence of nitrogenous and carbonaceous disinfection byproducts in drinking water distributed in Shenzhen, China. Chemosphere, 2017, 188: 257-264

150. Sobsey M D, Stauber C E, Casanova L M, Brown J M, Elliott M A. Point of use household drinking water filtration: a practical, effective solution for providing sustained access to safe drinking water in the developing world. Environmental Science \& Technology, 2008, 42(12): 4261-4267

151. Peter-Varbanets M, Zurbrügg C, Swartz C, Pronk W. Decentralized systems for potable water and the potential of membrane technology. Water Research, 2009, 43(2): 245-265

152. Pooi C K, Ng H Y. Review of low-cost point-of-use water treatment systems for developing communities. npj Clean Water, 2018, 1(1): 1-8

153. Li H, Chen Y, Zhang J, Dong B. Pilot study on nanofiltration membrane in advanced treatment of drinking water. Water Supply, 2020, 20(6): 2043-2053

154. Li X, Chua H, Sun J. Advanced drinking water treatment by a NF membrane system. HKIE Transactions, 2002, 9(1): 46-50

155. Yang H, Sun Y, Zhong W, Wu T, Tian Y, Li S. Pretreatment of locomotive direct drinking water by nanofiltration. In: Third International Conference on Transportation Engineering (ICTE). Reston: American Society of Civil Engineers, 2011, 3262-3267

156. Song N, Gao X, Ma Z, Wang X, Wei Y, Gao C. A review of graphene-based separation membrane: materials, characteristics, preparation and applications. Desalination, 2018, 437: 59-72 
157. Liu Y, Zhao Y, Zhang X, Huang X, Liao W, Zhao Y. MoS ${ }_{2}$-based membranes in water treatment and purification. Chemical Engineering Journal, 2021, 422: 130082

158. Wang H, Zeng Z, Xu P, Li L, Zeng G, Xiao R, Tang Z, Huang D, Tang L, Lai C, et al. Recent progress in covalent organic framework thin films: fabrications, applications and perspectives. Chemical Society Reviews, 2019, 48(2): 488-516

159. Peiris R H, Hallé C, Budman H, Moresoli C, Peldszus S, Huck P $\mathrm{M}$, Legge R L. Identifying fouling events in a membrane-based drinking water treatment process using principal component analysis of fluorescence excitation-emission matrices. Water Research, 2010, 44(1): 185-194

160. Chon K, Cho J. Fouling behavior of dissolved organic matter in nanofiltration membranes from a pilot-scale drinking water treatment plant: an autopsy study. Chemical Engineering Journal, 2016, 295: 268-277

161. Shao S, Fu W, Li X, Shi D, Jiang Y, Li J, Gong T, Li X. Membrane fouling by the aggregations formed from oppositely charged organic foulants. Water Research, 2019, 159: 95-101

162. Tang C Y, Chong T, Fane A G. Colloidal interactions and fouling of NF and RO membranes: a review. Advances in Colloid and Interface Science, 2011, 164(1-2): 126-143

163. Guo W, Ngo H H, Li J. A mini-review on membrane fouling. Bioresource Technology, 2012, 122: 27-34

164. Jiang S, Li Y, Ladewig B P. A review of reverse osmosis membrane fouling and control strategies. Science of the Total Environment, 2017, 595: 567-583

165. Kasemset S, Lee A, Miller D J, Freeman B D, Sharma M M. Effect of polydopamine deposition conditions on fouling resistance, physical properties, and permeation properties of reverse osmosis membranes in oil/water separation. Journal of Membrane Science, 2013, 425-426: 208-216

166. Guo H, Yao Z, Wang J, Yang Z, Ma X, Tang C Y. Polydopamine coating on a thin film composite forward osmosis membrane for enhanced mass transport and antifouling performance. Journal of Membrane Science, 2018, 551: 234-242

167. Liu M, Chen Q, Wang L, Yu S, Gao C. Improving fouling resistance and chlorine stability of aromatic polyamide thin-film composite ro membrane by surface grafting of polyvinyl alcohol (PVA). Desalination, 2015, 367: 11-20

168. Guo H, Deng Y, Yao Z, Yang Z, Wang J, Lin C, Zhang T, Zhu B, Tang C Y. A highly selective surface coating for enhanced membrane rejection of endocrine disrupting compounds: mechanistic insights and implications. Water Research, 2017, 121: 197203

169. Hoek E M, Bhattacharjee S, Elimelech M. Effect of membrane surface roughness on colloid-membrane DLVO interactions.
Langmuir, 2003, 19(11): 4836-4847

170. Shang C, Pranantyo D, Zhang S. Understanding the roughnessfouling relationship in reverse osmosis: mechanism and implications. Environmental Science \& Technology, 2020, 54(8): 52885296

171. Shang W, Sun F, Jia W, Guo J, Yin S, Wong P W, An A K. Highperformance nanofiltration membrane structured with enhanced stripe nano-morphology. Journal of Membrane Science, 2020, 600: 117852

172. Yang Z, Wu Y, Wang J, Cao B, Tang C Y. In situ reduction of silver by polydopamine: a novel antimicrobial modification of a thin-film composite polyamide membrane. Environmental Science \& Technology, 2016, 50(17): 9543-9550

173. Lu X, Feng X, Werber J R, Chu C, Zucker I, Kim J H, Osuji C O, Elimelech M. Enhanced antibacterial activity through the controlled alignment of graphene oxide nanosheets. Proceedings of the National Academy of Sciences of the United States of America, 2017, 114(46): E9793-E9801

174. Shi D, Liu Y, Fu W, Li J, Fang Z, Shao S. A combination of membrane relaxation and shear stress significantly improve the flux of gravity-driven membrane system. Water Research, 2020, 175: 115694

175. Gohil J M, Suresh A K. Chlorine attack on reverse osmosis membranes: mechanisms and mitigation strategies. Journal of Membrane Science, 2017, 541: 108-126

176. Do V T, Tang C Y, Reinhard M, Leckie J O. Effects of chlorine exposure conditions on physiochemical properties and performance of a polyamide membrane-mechanisms and implications. Environmental Science \& Technology, 2012, 46(24): 1318413192

177. Stolov M, Freger V. Degradation of polyamide membranes exposed to chlorine: an impedance spectroscopy study. Environmental Science \& Technology, 2019, 53(5): 2618-2625

178. Xu J, Wang Z, Yu L, Wang J, Wang S. A novel reverse osmosis membrane with regenerable anti-biofouling and chlorine resistant properties. Journal of Membrane Science, 2013, 435: 80-91

179. Liang Y, Zhu Y, Liu C, Lee K R, Hung W S, Wang Z, Li Y, Elimelech $\mathrm{M}$, Jin $\mathrm{J}$, Lin S. Polyamide nanofiltration membrane with highly uniform sub-nanometre pores for sub-1 precision separation. Nature Communications, 2020, 11(1): 1-9

180. Tan Z, Chen S, Peng X, Zhang L, Gao C. Polyamide membranes with nanoscale turing structures for water purification. Science, 2018, 360(6388): 518-521

181. Xu J, Wang Z, Wang J, Wang S. Positively charged aromatic polyamide reverse osmosis membrane with high anti-fouling property prepared by polyethylenimine grafting. Desalination, 2015, 365: 398-406 